\title{
RNAseq Reveals Differential Gene Expression Contributing to Phytophthora nicotianae Adaptation to Partial Resistance in Tobacco
}

\author{
Jing Jin ${ }^{1, *}$, Rui Shi ${ }^{2}{ }^{\oplus}$, Ramsey Steven Lewis ${ }^{2}$ and Howard David Shew ${ }^{1}$ \\ 1 Department of Entomology and Plant Pathology, North Carolina State University, Raleigh, NC 27695, USA; \\ shew@ncsu.edu \\ 2 Department of Crop and Soil Science, North Carolina State University, Raleigh, NC 27695, USA; \\ rshi@ncsu.edu (R.S.); rslewis@ncsu.edu (R.S.L.) \\ * Correspondence: jjin2@ncsu.edu
}

check for updates

Citation: Jin, J.; Shi, R.; Lewis, R.S.; Shew, H.D. RNAseq Reveals Differential Gene Expression Contributing to Phytophthora nicotianae Adaptation to Partial Resistance in Tobacco. Agronomy 2021, 11, 656. https://doi.org/10.3390/ agronomy11040656

Academic Editors: Fengjie Sun and Gustavo Caetano-Anollés

Received: 28 February 2021

Accepted: 26 March 2021

Published: 30 March 2021

Publisher's Note: MDPI stays neutral with regard to jurisdictional claims in published maps and institutional affiliations.

Copyright: (c) 2021 by the authors. Licensee MDPI, Basel, Switzerland. This article is an open access article distributed under the terms and conditions of the Creative Commons Attribution (CC BY) license (https:/ / creativecommons.org/licenses/by/ $4.0 /)$.

\begin{abstract}
Phytophthora nicotianae is a devastating oomycete plant pathogen with a wide host range. On tobacco, it causes black shank, a disease that can result in severe economic losses. Deployment of host resistance is one of the most effective means of controlling tobacco black shank, but adaptation to complete and partial resistance by P. nicotianae can limit the long-term effectiveness of the resistance. The molecular basis of adaptation to partial resistance is largely unknown. RNAseq was performed on two isolates of P. nicotianae (adapted to either the susceptible tobacco genotype Hicks or the partially resistant genotype $\mathrm{K} 326 \mathrm{Wz} / \mathrm{Wz}$ ) to identify differentially expressed genes (DEGs) during their pathogenic interactions with K $326 \mathrm{Wz} / \mathrm{Wz}$ and Hicks. Approximately $69 \%$ of the up-regulated DEGs were associated with pathogenicity in the $\mathrm{K} 326 \mathrm{Wz} / \mathrm{Wz}$-adapted isolate when sampled following infection of its adapted host $\mathrm{K} 326 \mathrm{Wz} / \mathrm{Wz}$. Thirty-one percent of the up-regulated DEGs were associated with pathogenicity in the Hicks-adapted isolate on $\mathrm{K} 326 \mathrm{Wz} / \mathrm{Wz}$. A broad spectrum of over-represented gene ontology (GO) terms were assigned to down-regulated genes in the Hicksadapted isolate. In the host, a series of GO terms involved in nuclear biosynthesis processes were assigned to the down-regulated genes in $\mathrm{K} 326 \mathrm{Wz} / \mathrm{Wz}$ inoculated with $\mathrm{K} 326 \mathrm{Wz} / \mathrm{Wz}$-adapted isolate. This study enhances our understanding of the molecular mechanisms of P. nicotianae adaptation to partial resistance in tobacco by elucidating how the pathogen recruits pathogenicity-associated genes that impact host biological activities.
\end{abstract}

Keywords: RNAseq; Phytophthora nicotianae; adaptation; partial resistance; tobacco

\section{Introduction}

Plant diseases are estimated to cause crop losses of $13 \%$ annually, imposing a major constraint on global crop production [1]. Deployment of complete and partial resistance in host plants is one of the most effective means of managing plant diseases and is an integral part of sustainable disease management that reduces the use of fungicides and other management inputs [2]. However, wide distribution of cultivars with complete resistance places strong selection pressure on pathogen populations to overcome that resistance [3]. Partial resistance selects for isolates that are more aggressive than isolates produced on susceptible cultivars, which can erode the effectiveness of partial resistance over time [4-6].

Various mechanisms utilized by plant pathogens to overcome complete resistance have been recognized, including loss of avirulence (Avr) gene products that trigger plant immunity, transposon insertions or mutations to the Avr gene sequence, acquisition of additional epistatic effectors that suppress the plant immune system without disrupting the original Avr gene [7], and endogenous small RNAs silencing Avr genes [8]. Despite our rapid improvement in understanding the molecular basis underlying complete resistance 
and how pathogens overcome it, mechanisms of plant pathogen adaptation to partial resistance remains largely unknown.

Phytophthora nicotianae is a widely prevalent plant pathogen with hosts in 255 genera from 90 plant families [9]. When infecting tobacco (Nicotiana tabacum L.), the pathogen causes black shank, a potentially devastating disease with losses reaching $100 \%$ in some fields [10]. The use of host resistance provides an effective system for reducing yield losses due to black shank, but isolates of $P$. nicotianae can rapidly adapt to genetic resistance in tobacco. Populations of P. nicotianae rapidly shifted from race 0 (wild type) to race 1 after deployment of tobacco varieties with the Php gene [11]. Deployment of partial resistance is generally thought to be a sustainable approach to managing plant diseases. However, adaptation to partial resistance in P. nicotianae has also been observed. A significant increase in pathogen aggressiveness was documented in isolates of $P$. nicotianae exposed to a tobacco variety with a high level of partial resistance [12-14]. A greenhouse study demonstrated that isolates of P. nicotianae were able to overcome partial resistance QTLs derived from cigar cultivar Florida 301 and the Wz genomic region from Nicotiana rustica after exposure for only a few host generations $[14,15]$. Phenotypically, isolates of $P$. nicotianae adapted to sources of partial resistance exhibited increased infection efficiency and produced more sporangia on infected root tips, larger lesions on tobacco stems, and more aggressive asexual progeny than isolates not adapted on the resistant hosts [16].

The goal of the present study was to explore the molecular mechanisms underlying P. nicotianae adaptation to $\mathrm{Wz}$-mediated partial resistance in tobacco genotype $\mathrm{K} 326 \mathrm{Wz} / \mathrm{Wz}$, which was developed using an elite flue-cured tobacco cultivar K 326 as the recipient of $\mathrm{Wz}$ with the backcross breeding method. RNA samples of two P. nicotianae isolates adapted on either partially resistant inbred tobacco parental line $\mathrm{K} 326 \mathrm{Wz} / \mathrm{Wz}$ or the very susceptible cultivar Hicks were collected following infection of their adapted and their non-adapted host genotypes and subjected to RNA sequencing (RNAseq). The changes in gene expression in the two isolates were investigated by comparing the DEGs identified in each of the two isolates when infecting $\mathrm{K} 326 \mathrm{Wz} / \mathrm{Wz}$ compared to infecting Hicks. In addition, DEGs were identified in infected root samples of $\mathrm{K} 326 \mathrm{Wz} / \mathrm{Wz}$ by comparing to gene expression in inoculated root samples of Hicks. The results from this study enhance our understanding of how pathogens adapt to partial resistance in host plants, which will help in the development of sound deployment strategies for partial resistance and help increase the durability of partial resistance in host plants in the future.

\section{Materials and Methods}

\subsection{RNAseq Preparation}

\subsubsection{Collection of Pathogen Isolates}

Two isolates of $P$. nicotianae were collected from a previous greenhouse study where a race 0 isolate of $P$. nicotianae adapted on tobacco genotype $\mathrm{K} 326 \mathrm{Wz} /$-(a genotype heterozygous for $\mathrm{Wz}$ ) was continually exposed to either $\mathrm{K} 326 \mathrm{Wz} / \mathrm{Wz}$ or the susceptible host Hicks. Isolates of $P$. nicotianae presented a significantly lower aggressiveness on $\mathrm{K} 326 \mathrm{Wz} / \mathrm{Wz}$ after exposure to Hicks compared to the isolates maintained on a host with $\mathrm{Wz}$ resistance. The two isolates selected for current study represented a broad spectrum of aggressiveness on $\mathrm{K} 326 \mathrm{Wz} / \mathrm{Wz}$ in the greenhouse aggressiveness evaluation. One isolate $(\mathrm{Wz}-\mathrm{Wz})$ was from $\mathrm{K} 326 \mathrm{Wz} / \mathrm{Wz}$ and had an aggressiveness index of 9.25 out of a possible 10. The second isolate $(\mathrm{Wz}-\mathrm{H})$ was from Hicks and had an aggressiveness index of 1.25. The aggressiveness index was converted from disease severity value caused by a given isolate. A disease severity value of 0 was given to plants that did not have above ground symptoms 28 days after inoculation. The severity values were: $1-6$ days $=0,7-10$ days $=8$, $11-16$ days $=6,17-22$ days $=4,23-28$ days $=2$, and no symptoms at day $28=0$ [17].

\subsubsection{Pathogen Culture and Tobacco Infection}

The two isolates were maintained on $5 \% \mathrm{~V} 8$ agar at $28{ }^{\circ} \mathrm{C}$ in the dark in an incubator. Mycelial plugs from the edge of the cultures grown on V8 were transferred to the center of 
Petri dishes containing oatmeal agar (Difco, Detroit, MI, USA). Petri dishes were incubated in the dark at $28^{\circ} \mathrm{C}$ for approximately 2 weeks until dense hyphal mats formed. Hyphal mats were peeled from the oatmeal agar surface and placed into Petri dishes containing $20 \mathrm{~mL}$ of sterile $5 \%$ sandy-loam soil extract. Five percent soil extract was prepared by mixing $50 \mathrm{~g}$ of soil with $1 \mathrm{~L}$ of deionized water and letting it sit at room temperature for $48 \mathrm{~h}$. The suspension was filtered through Fisher Brand Qualitative P8 filter paper and Celite 545 (Fisher Scientific, Fair Lawn, NJ, USA), and sterilized by autoclaving for two consecutive days at $121^{\circ} \mathrm{C}$ for $60 \mathrm{~min}$. Petri dishes were placed under constant light at room temperature in laboratory for about 5 days at which time numerous sporangia had produced. Sterile $5 \%$ soil extract was replaced daily during incubation. Zoospores were released by incubating hyphal mats at $4{ }^{\circ} \mathrm{C}$ for $1 \mathrm{~h}$, followed by incubation at $28^{\circ} \mathrm{C}$ for $30 \mathrm{~min}$. The concentration of zoospore suspension was determined and adjusted to a concentration of $1 \times 10^{5}$ zoospores $/ \mathrm{mL}$ using a hemocytometer.

Tobacco seeds of $\mathrm{K} 326 \mathrm{Wz} / \mathrm{Wz}$ and Hicks were seeded in potting mix (Fafard 2 Mix; Conrad Fafard, Inc., Agawam, MA, USA) in plastic pots in a greenhouse with a $35^{\circ} \mathrm{C} / 26{ }^{\circ} \mathrm{C}$ day/night temperature regime and a $14 \mathrm{~h}$ photoperiod supplemented with high intensity lights. After two weeks, germinated seedlings were transplanted to cell trays (cell size $3.8 \mathrm{~cm} \times 3.8 \mathrm{~cm} \times 5.7 \mathrm{~cm}$ ) containing calcined clay $\left(\right.$ TURFACE $^{\circledR}$ All Sport ${ }^{\mathrm{TM}}$, PROFILE Products LLC, Buffalo Grove, IL, USA) and grown for about two weeks. Six seedlings of each genotype were removed from calcined clay, washed gently with sterile deionized water, and inoculated by immersing the roots for $3 \mathrm{~h}$ in $60 \mathrm{~mL}$ of zoospore suspension of one of the two isolates in a Petri dish $(25 \times 100 \mathrm{~mm})$. After inoculation, seedlings were moved to a new Petri dish $(25 \times 100 \mathrm{~mm})$ containing $60 \mathrm{~mL}$ of $5 \%$ soil extract and incubated under constant light at room temperature. Forty-eight hours post inoculation (hpi), roots of individual seedlings were flash frozen in liquid nitrogen in separate $1.7 \mathrm{~mL}$ centrifuge tubes and subjected to RNA extraction.

\subsubsection{RNA Isolation and Transcriptome Sequencing}

A total of 24 infected root samples $(2$ isolates $\times 2$ tobacco genotypes $\times 6$ biological replicates) were subjected to RNA isolation. Total RNA of infected roots of each seedling was extracted using Qiagen Plant RNeasy Kits (Qiagen, Hilden, Germany) following the manufacturer's instructions. Genomic DNA was removed by on-column digestion with DNase I (Zymo Research Corporation, Irvine, CA, USA). The concentration and quality of total RNA were determined by BioAnalyzer RNA analysis. Three of the six biological replicates of each treatment with the highest RNA quality were selected for RNA sequencing.

RNA library preparation and sequencing were conducted at the Genomic Science Library at North Carolina State University (Raleigh, NC, USA). Briefly, the RNAseq library was constructed using a NEBNext ${ }^{\circledR}$ Ultra $^{\mathrm{TM}}$ Directional RNA library Prep Kit for Illumina (New England BioLabs, Ipswish, MA, USA) using $1 \mu \mathrm{g}$ of each of the RNA samples followed by a 350-500 bp final library size selection. Libraries of the three biological replicates for each of the four treatments ( 2 isolates $\times 2$ tobacco genotypes) were multiplexed and sequenced in a single Illumina NextSeq 500 lane, generating 75 bp paired-end reads.

\subsection{Analyses of RNAseq Data from P. nicotianae}

\subsubsection{Detection of Differentially Expressed Genes (DEGs) in P. nicotianae}

Sequence quality was assessed using FastQC v0.11.8 [18]. No trimming was performed since the Phred quality score of each sequenced base was above 30 for all samples. Reads of all samples were aligned to the P. nicotianae genome (phytophthora_parasitica_inra_ 310.3.scaffolds.fasta) using Hisat2 v2.1.0 [19] with default parameters and maximum intron length of $5000 \mathrm{bp}$.

Reads mapped to coding sequences (CDS) of annotated genes were counted using featureCounts [20] with default settings. DEGs in a given isolate were identified by comparing infected $\mathrm{K} 326 \mathrm{Wz} / \mathrm{Wz}$ samples to infected Hicks samples using edgeR [21] with 
TMM normalization, a generalized linear model, and false discovery rate (FDR) calculations based on the Benjamini-Hochberg method. Genes with a false FDR $<0.05$ were considered to be DEGs. DEGs were divided into up- and down-regulated groups for further analyses.

\subsubsection{Gene Ontology Analysis, KEGG Pathway Enrichment Analysis and PHIB-Blast}

Gene Ontology (GO) ID and protein sequences were linked to individual DEGs using the UniProt website (https: / / www.uniprot.org/. Accessed on 21 May 2019) [22]. GO term enrichment analysis was performed using the BiNGO plugin [23] in Cytoscape v3.7.1 [24]. Over-represented GO terms were evaluated against the P. nicotianae genome in the categories "biological process", "molecular function", and "cellular component". The DEGs were subjected to the Kyoto Encyclopedia of Genes and Genomes (KEGG) [25] pathway enrichment analysis to understand their roles in biological pathways using KOBAS [26] with background species set to Phytophthora infestans, statistical method set to Hypergeometric test/Fisher's exact test, and FDR correction method set to Benjamini and Hochberg. Protein sequences of the DEGs were subjected to a blast search in PHIB-Pathogen Host Interactions base [27] to identify DEGs associated with pathogenicity. A DEG was considered pathogenicity-associated if it or its ortholog was verified in association with "loss of pathogenicity", "reduced virulence", "lethal", or "effector" in pathogens with an Evalue cutoff of $1.0 \times 10^{-5}$.

\subsubsection{Detection of Differential Transcript Usage}

To detect differential transcript usage, transcripts in each sample were assembled and quantified using StringTie [28] by comparing the BAM file (aligned using Hisat2) to the annotated reference genome (phytophthora_parasitica_inra_310.3.genes.gtf). Analysis of alternative splicing and isoform switches was conducted using IsoformSwitchAnalyzeR [29] package in $\mathrm{R}$. Isoforms in each isolate of $P$. nicotianae found by comparing infected samples of $\mathrm{K} 326 \mathrm{Wz} / \mathrm{Wz}$ to infected samples of Hicks were considered differentially switched if difference in isoform fraction $(\mathrm{dIF})>0.1$ and FDR corrected q-value $<0.05$. Genes with differential transcript usage were subject to GO, KEGG, and PHIB blast analyses as well.

\subsubsection{Identification of Single-Nucleotide Polymorphisms (SNPs)}

To identify SNPs in the two isolates of P. nicotianae, sorted bam files of individual samples were subjected to variant calling using samtools mpileup and filtered using bcftools [30]. SNPs identified between the two isolates were located in genes. Gene sequences and corresponding protein sequences were blasted in NCBI to further identify their potential roles in aggressiveness in each of the two isolates of P. nicotianae.

\subsection{Analyses of RNAseq Data from N. tabacum}

\subsubsection{Detection of Differentially Expressed Genes (DEGs) in N. tabacum}

Reads of all samples were aligned to the Nicotiana tabacum genome [31] using Hisat2 v2.1.0 [19]. Reads mapped to coding sequences (CDS) of annotated genes were counted using featureCounts [20] with default settings. DEGs in $\mathrm{K} 326 \mathrm{Wz} / \mathrm{Wz}$ inoculated with a given isolate were identified by comparing it to Hicks inoculated with the same isolate by edgeR [21] using TMM normalization, a generalized linear model, and false discovery rate (FDR) calculations based on the Benjamini-Hochberg method. Genes with a false FDR $<0.05$ were considered DEGs. DEGs were divided into up- and down-regulated datasets for further analysis.

\subsubsection{Gene Ontology and KEGG Enrichment Analyses}

DEGs were subjected to GO enrichment analysis using AgriGO v2 [32] against Nitab4.5 ID (solgenomics) as background with default settings. Corresponding protein sequences of DEGs were extracted and subjected to KEGG enrichment analysis using KOBAS [26] with background species set to Nicotiana tabacum, statistical method set to Hypergeometric test/Fisher's exact test, and FDR correction method set to Benjamini and Hochberg. 


\subsection{Quantitative Real-Time PCR ( $q$ RT-PCR) Validations}

Two up-regulated and two down-regulated DEGs detected in both of the two P. nicotianae isolates with largest fold changes (Table 1) were chosen for qRT-PCR quantification to validate the DEGs called in RNAseq analysis. RNA samples extracted from two biological samples of each treatment were used as templates in qRT-PCR validations. First strand cDNA synthesis was initiated using ProtoScript ${ }^{\circledR I I}$ reverse transcriptase (New England Biolabs, Beverly, MA, USA) following first strand cDNA synthesis standard protocol NEB\#M0277. The ubiquitin-conjugating enzyme $(\mathrm{Ubc})$ and the $40 \mathrm{~S}$ ribosomal protein S3A (WS21), constitutively expressed throughout $P$. nicotianae development stages, were used as internal control genes [33] (Table 1).

Table 1. Genes and corresponding primers used for qRT-PCR validation.

\begin{tabular}{cccc}
\hline Gene & Regulation & Forward Primer & Reverse Primer \\
\hline PPTG_10666 & Up & CGTTCTCTTTTGCTCACGGA & CAGCTCCGACAAGTACACTG \\
PPTG_19949 & Up & CAACACTGTCACTGCTGGAT & GATCCAGTTGCTAGCGAGAG \\
PPTG_20266 & Down & CTCTCCGAAACAGAACCAACT & GTAGATCTCGGCAGTAACGC \\
PPTG_08585 & Down & AACACCACTACTCCAGCACT & ACAACTTCACCACATCCGTC \\
Ubc (ubiquitin-conjugating enzyme) & & CCACTTAGAGCACGCTAGGA & TACCGACTGTCCTTCGTTCA \\
WS21 (40S ribosomal protein S3A) & & TACGCCAAGACGGCTCAGA & TTCCATCAGACGCACCAGG \\
\hline
\end{tabular}

A total of $20 \mu \mathrm{L}$ of reaction solution, including $1 \mu \mathrm{L}$ of cDNA, $10 \mu \mathrm{L}$ of iTaq Universal SYBR Green SuperMix (BioRad, Hercules, CA, USA), $0.6 \mu \mathrm{L}$ of forward and $0.6 \mu \mathrm{L}$ of reverse primers $(10 \mu \mathrm{M})$, and $7.8 \mu \mathrm{L}$ of molecular grade water was used for qRT-PCR. qRT-PCR was performed on 96-well plates using the Applied Biosystems QuantStudioTM 6 Flex Real-Time PCR system with the following settings: one cycle of $95^{\circ} \mathrm{C}$ for $20 \mathrm{~s}$ (hold stage), followed by 40 cycles of $95^{\circ} \mathrm{C}$ for $15 \mathrm{~s}, 60^{\circ} \mathrm{C}$ for $30 \mathrm{~s}$ (PCR stage), with a final melt curve stage: $95^{\circ} \mathrm{C}$ for $15 \mathrm{~s}, 60^{\circ} \mathrm{C}$ for $1 \mathrm{~min}$ and $95^{\circ} \mathrm{C}$ for $15 \mathrm{~s}$. Three technical replicates were performed for each sample and primer set combination.

\section{Results}

\subsection{RNAseq Overview}

\subsubsection{Infected Tobacco Root Samples for RNAseq}

Root tissue colonized by P. nicotianae was obtained for RNAseq by inoculating and harvesting the roots of seedlings $48 \mathrm{~h}$ post inoculation (hpi). At $48 \mathrm{hpi}$, slight browning of the roots was present and abundant sporangia were present around roots.

\subsubsection{RNA Sequencing and Sequence Mapping to the Reference Genome}

Approximately 33 million reads were obtained per sample. An average of $27 \%$ of the reads were mapped to the $P$. nicotianae genome and an average of $6 \%$ of the reads were mapped to the N. tabacum genome (Table 2).

\subsection{Overview of DEGs in P. nicotianae}

\subsubsection{DEGs Identified in P. nicotianae}

For each of the two isolates, DEGs were identified by comparing infected K $326 \mathrm{Wz} / \mathrm{Wz}$ samples to infected Hicks samples. The DEGs identified in the two isolates were compared to view the dynamics in gene expression in the two isolates after infecting their adapted and their non-adapted tobacco host genotypes.

Forty-six genes in $\mathrm{Wz}-\mathrm{Wz}$ and 50 genes in $\mathrm{Wz}-\mathrm{H}$ isolates were differentially expressed. Specifically, 16 up-regulated and 30 down-regulated genes were identified in the $\mathrm{Wz}-\mathrm{Wz}$ isolate (Table 3), and 29 up-regulated and 21 down-regulated genes were detected in the $\mathrm{Wz}$-H isolate (Table 4). qRT-PCR of the four selected DEGs indicated expression pattern consistent with those captured in RNAseq where PPTG_08585 and PPTG_20266 had a lower 
expression, and PPTG_10666 and PPTG_19949 had a higher expression in the two isolates when infecting K $326 \mathrm{Wz} / \mathrm{Wz}$ comparing to when they were infecting Hicks (Figure 1).

Both isolates up-regulated genes PPTG_19949,PPTG_06767,PPTG_10666,PPTG_05470 that encode uncharacterized proteins in P. nicotianae, and down-regulated 8 genes including genes that encode $60 \mathrm{~S}$ ribosomal protein L38, phosphoadenosine phosphosulfate reductase, and $\mathrm{NAD}(\mathrm{P}) \mathrm{H}$ :quinone oxidoreductase.

Thirty-four DEGs were detected exclusively in the $W z-W z$ isolate. Most of these genes encoded for uncharacterized proteins in $P$. nicotianae. Up-regulated genes with known function included PPTG_02121, PPTG_08145, and PPTG_12158 that encode Hsp70like protein, 4-aminobutyrate transaminase, and ULK/ULK protein kinase. Similarly, the majority of the 38 DEGs identified only in the $W z-H$ isolate encoded for uncharacterized proteins. Genes with known function included an up-regulated gene, PPTG_17442, that encodes protein-S-isoprenylcysteine O-methyltransferase and down-regulated genes, PPTG_17561,PPTG_00501,PPTG_21942, and PPTG_15084 predicted to encode for a glycine cleavage system $\mathrm{H}$ protein, homoserine $\mathrm{O}$-acetyltransferase, phosphate acetyltransferase, and TKL/DRK protein kinase.

Table 2. Summary of RNAseq data and mapping results.

\begin{tabular}{|c|c|c|c|c|c|c|c|}
\hline \multirow[b]{2}{*}{$\begin{array}{c}\text { Host } \\
\text { Genotype }\end{array}$} & \multirow[b]{2}{*}{$\begin{array}{l}\text { Isolate for } \\
\text { Inoculation }\end{array}$} & \multirow[b]{2}{*}{ Replication } & \multirow[b]{2}{*}{ Total Reads } & \multicolumn{2}{|c|}{ P. nicotianae } & \multicolumn{2}{|c|}{ N. tabacum } \\
\hline & & & & $\begin{array}{c}\text { No. and Rate } \\
\text { of Reads } \\
\text { Mapped }\end{array}$ & $\begin{array}{c}\text { Overall } \\
\text { Alignment } \\
\text { Rate }\end{array}$ & $\begin{array}{l}\text { No. and Rate } \\
\text { of Reads } \\
\text { Mapped }\end{array}$ & $\begin{array}{c}\text { Overall } \\
\text { Alignment } \\
\text { Rate }\end{array}$ \\
\hline Hicks & $W z-\mathrm{H}$ & 1 & $32,616,245$ & $\begin{array}{c}11,799,948 \\
(36.18 \%)\end{array}$ & $38.50 \%$ & $\begin{array}{c}1,170,706 \\
(3.59 \%)\end{array}$ & $4.77 \%$ \\
\hline Hicks & $W z-\mathrm{H}$ & 2 & $37,590,753$ & $\begin{array}{l}8,954,805 \\
(23.82 \%)\end{array}$ & $25.42 \%$ & $\begin{array}{l}691,568 \\
(1.84 \%)\end{array}$ & $2.55 \%$ \\
\hline Hicks & $W z-\mathrm{H}$ & 3 & $32,142,283$ & $\begin{array}{l}8,581,032 \\
(26.70 \%)\end{array}$ & $28.55 \%$ & $\begin{array}{c}1,526,273 \\
(4.75 \%)\end{array}$ & $6.21 \%$ \\
\hline $\mathrm{K} 326 \mathrm{Wz} / \mathrm{Wz}$ & $W z-\mathrm{H}$ & 1 & $30,738,911$ & $\begin{array}{l}6,756,839 \\
(21.98 \%)\end{array}$ & $23.62 \%$ & $\begin{array}{c}1,234,275 \\
(4.02 \%)\end{array}$ & $5.84 \%$ \\
\hline $\mathrm{K} 326 \mathrm{Wz} / \mathrm{Wz}$ & $W z-\mathrm{H}$ & 2 & $32,228,624$ & $\begin{array}{c}7,512,158 \\
(23.31 \%)\end{array}$ & $24.89 \%$ & $\begin{array}{c}2,571,539 \\
(7.98 \%)\end{array}$ & $10.15 \%$ \\
\hline K $326 \mathrm{Wz} / \mathrm{Wz}$ & $W z-\mathrm{H}$ & 3 & $41,304,137$ & $\begin{array}{l}8,159,363 \\
(19.75 \%)\end{array}$ & $21.14 \%$ & $\begin{array}{c}1,146,835 \\
(2.78 \%)\end{array}$ & $3.63 \%$ \\
\hline Hicks & $W z-W z$ & 1 & $32,441,520$ & $\begin{array}{l}8,583,661 \\
(26.46 \%)\end{array}$ & $28.35 \%$ & $\begin{array}{c}1,003,943 \\
(3.09 \%)\end{array}$ & $4.19 \%$ \\
\hline Hicks & $W z-W z$ & 2 & $33,639,749$ & $\begin{array}{c}6,441,805 \\
(19.15 \%)\end{array}$ & $20.54 \%$ & $\begin{array}{l}561,746 \\
(1.67 \%)\end{array}$ & $2.95 \%$ \\
\hline Hicks & $W z-W z$ & 3 & $30,538,468$ & $\begin{array}{c}10,333,429 \\
(33.84 \%)\end{array}$ & $36.10 \%$ & $\begin{array}{l}557,494 \\
(1.83 \%)\end{array}$ & $2.91 \%$ \\
\hline K $326 \mathrm{Wz} / \mathrm{Wz}$ & $W z-W z$ & 1 & $32,424,684$ & $\begin{array}{c}9,437,437 \\
(29.11 \%)\end{array}$ & $31.12 \%$ & $\begin{array}{c}5,499,898 \\
(16.96 \%)\end{array}$ & $20.63 \%$ \\
\hline K $326 \mathrm{Wz} / \mathrm{Wz}$ & $W z-W z$ & 2 & $34,550,232$ & $\begin{array}{c}7,129,753 \\
(20.64 \%)\end{array}$ & $22.21 \%$ & $\begin{array}{l}412,999 \\
(1.20 \%)\end{array}$ & $1.98 \%$ \\
\hline \multirow[t]{2}{*}{ K $326 \mathrm{Wz} / \mathrm{Wz}$} & $W z-W z$ & 3 & $30,323,291$ & $\begin{array}{l}7,477,321 \\
(24.66 \%)\end{array}$ & $26.38 \%$ & $\begin{array}{l}852,994 \\
(2.81 \%)\end{array}$ & $4.20 \%$ \\
\hline & & Average & $33,378,241$ & & $27.23 \%$ & & $5.83 \%$ \\
\hline
\end{tabular}


Table 3. DEGs identified in the $W z-W z$ isolate of $P$. nicotianae by comparing transcriptomes in inoculated $\mathrm{K} 326 \mathrm{Wz} / \mathrm{Wz}$ to inoculated Hicks.

\begin{tabular}{|c|c|c|c|}
\hline Up-Regulated Gene & $\operatorname{logFC}$ & FDR & Annotation in NCBI \\
\hline PPTG_02121 & 2.72729992 & 0.04116515 & $\begin{array}{l}\text { Nucleotide-Binding Domain of the sugar } \\
\text { kinase/HSP70/actin superfamily }\end{array}$ \\
\hline PPTG_10666 & 1.40170745 & 0.00461859 & NADB_Rossmann \\
\hline PPTG_12300 & 1.38934498 & 0.0113136 & Elicitin protein RAL13D [Phytophthora nicotianae] \\
\hline PPTG_06767 & 1.29785829 & 0.00975047 & Cytochrome P450 \\
\hline PPTG_00731 & 1.14244371 & 0.02689335 & $\begin{array}{l}\text { Mitochondrial succinate-semialdehyde dehydrogenase and ALDH } \\
\text { family members } 5 \mathrm{~A} 1 \text { and } 5 \mathrm{~F} 1 \text {-like }\end{array}$ \\
\hline PPTG_08145 & 1.06166001 & 0.03655436 & 4-aminobutyrate aminotransferase or related aminotransferase \\
\hline PPTG_01316 & 1.01159768 & 0.0113136 & $\begin{array}{l}\text { Aspartate aminotransferase (AAT) superfamily (fold type I) of } \\
\text { pyridoxal phosphate (PLP)-dependent enzymes }\end{array}$ \\
\hline PPTG_06886 & 0.9770123 & 0.04116515 & Mitochondrial carrier protein \\
\hline PPTG_00433 & 0.95687542 & 0.04116515 & Amino acid permease \\
\hline PPTG_05470 & 0.94439287 & 0.00975047 & SPRY domain in Ran binding proteins, SSH4, HECT E3 and SPRYD3 \\
\hline PPTG_19949 & 0.90621478 & 0.01386612 & Peptidase domain in the S8 and S53 families \\
\hline PPTG_08778 & 0.89782849 & 0.0287979 & NA \\
\hline PPTG_11182 & 0.89467137 & 0.04116515 & GAF domain \\
\hline PPTG_10595 & 0.88099898 & 0.02633833 & $\begin{array}{l}\text { Second domain of the pleiotropic drug resistance-like (PDR) } \\
\text { subfamily G of ATP-binding cassette transporters }\end{array}$ \\
\hline PPTG_05834 & 0.80783638 & 0.01128107 & Putative lectin [Phytophthora palmivora var. palmivora] \\
\hline PPTG_12158 & 0.63468318 & 0.02633833 & Serine/Threonine protein kinases, catalytic domain \\
\hline Down-Regulated Gene & $\log \mathrm{FC}$ & FDR & Annotation in NCBI \\
\hline PPTG_12754 & -0.6308213 & 0.04116515 & 60S ribosomal protein L38 \\
\hline PPTG_19261 & -0.6513629 & 0.01740912 & WRKY transcription factor 19 [Phytophthora nicotianae] \\
\hline PPTG_15145 & -0.7844201 & 0.04116515 & Scavenger mRNA decapping enzyme C-term binding \\
\hline PPTG_00424 & -0.8320101 & 0.04116515 & Amino acid permease \\
\hline PPTG_19041 & -0.9101204 & 0.02968312 & acetate kinase $\mathrm{A}$ /propionate kinase 2 \\
\hline PPTG_00957 & -0.9268608 & 0.04550147 & NA \\
\hline PPTG_00099 & -0.9276355 & 0.03028585 & NA \\
\hline PPTG_11197 & -1.01735 & 0.03970974 & $\begin{array}{l}\text { 3'-phosphoadenosine } 5^{\prime} \text {-phosphosulfate sulfotransferase } \\
\text { (PAPS reductase)/FAD synthetase or related enzyme }\end{array}$ \\
\hline PPTG_09433 & -1.2431276 & 0.02997457 & Major Facilitator Superfamily (MFS) proteins \\
\hline PPTG_17813 & -1.2434395 & 0.04550147 & Ankyrin repeats \\
\hline PPTG_04568 & -1.3541329 & 0.0459794 & PQ-loop \\
\hline PPTG_02974 & -1.4004705 & 0.03655436 & Major Facilitator Superfamily (MFS) proteins \\
\hline PPTG_02595 & -1.49923 & 0.03655436 & NAD(P)+-dependent aldehyde dehydrogenase superfamily \\
\hline PPTG_11386 & -1.5047674 & 0.02633833 & NA \\
\hline PPTG_07126 & -1.5248213 & 0.04304619 & Short chain dehydrogenase \\
\hline PPTG_12006 & -1.5957463 & 0.01170615 & Glycosyl hydrolase family 1 \\
\hline PPTG_08585 & -1.6180257 & 0.00106403 & Old yellow enzyme (OYE)-like FMN binding domain \\
\hline PPTG_18570 & -1.633993 & 0.01009357 & Zinc finger, $\mathrm{C} 2 \mathrm{H} 2$ type \\
\hline PPTG_23779 & -1.6347597 & 0.00427631 & $\begin{array}{c}\text { NAD(P)H:FMN oxidoreductases, oxygen-insensitive nitroreductase, } \\
\text { flavin reductase } \mathrm{P} \text {, dihydropteridine reductase, NADH oxidase or } \\
\text { NADH dehydrogenase }\end{array}$ \\
\hline PPTG_05530 & -1.6929325 & 0.01258482 & NADPH oxidase (NOX) \\
\hline PPTG_02448 & -1.7462909 & 0.00975047 & Major Facilitator Superfamily (MFS) proteins \\
\hline PPTG_18743 & -1.7855609 & 0.03655436 & NA \\
\hline PPTG_13181 & -2.0941462 & 0.01009357 & Major Facilitator Superfamily (MFS) proteins \\
\hline PPTG_08485 & -2.1192135 & 0.02633833 & Major Facilitator Superfamily (MFS) proteins \\
\hline PPTG_09275 & -2.1770096 & 0.0000271 & NADPH-dependent FMN reductase \\
\hline PPTG_00236 & -2.2019316 & 0.02968312 & TonB receptor activity [Phytophthora megakarya] \\
\hline PPTG_13068 & -2.3667825 & 0.03655436 & Membrane-associating domain \\
\hline PPTG_20266 & -2.4697411 & 0.00888653 & NADPH-dependent FMN reductase \\
\hline PPTG_04065 & -3.3756258 & 0.03655436 & ZIP Zinc transporter \\
\hline PPTG_10399 & -3.9114676 & 0.01740912 & $\begin{array}{c}\text { D-arabinose 1-dehydrogenase, } \mathrm{Zn} \text {-dependent alcohol } \\
\text { dehydrogenase family }\end{array}$ \\
\hline
\end{tabular}


Table 4. DEGs identified in $\mathrm{Wz}-\mathrm{H}$ isolate of $P$. nicotianae by comparing transcriptomes in inoculated $\mathrm{K} 326 \mathrm{Wz} / \mathrm{Wz}$ to inoculated Hicks.

\begin{tabular}{|c|c|c|c|}
\hline Up-Regulated Gene & $\operatorname{logFC}$ & FDR & Annotation in NCBI \\
\hline PPTG_01162 & 1.75973946 & 0.03399441 & Exonuclease-Endonuclease-Phosphatase (EEP) domain superfamily \\
\hline PPTG_01484 & 1.66331002 & 0.01294692 & Amino_oxidase; Flavin containing amine oxidoreductase \\
\hline PPTG_08721 & 1.36573335 & 0.03296512 & SCP-like extracellular protein domain \\
\hline PPTG_12693 & 1.35565787 & 0.0217849 & NA \\
\hline PPTG_15982 & 1.22889916 & 0.03661908 & NAD $(\mathrm{P})$-dependent dehydrogenase \\
\hline PPTG_17442 & 1.14815854 & 0.03856894 & Isoprenylcysteine carboxyl methyltransferase (ICMT) family \\
\hline PPTG_19949 & 1.09394216 & 0.00569986 & Peptidase domain in the S8 and S53 families \\
\hline PPTG_06767 & 1.09239542 & 0.02680104 & Cytochrome P450 \\
\hline PPTG_10666 & 1.05056269 & 0.02831652 & Rossmann-fold NAD $(\mathrm{P})(+)$-binding proteins \\
\hline PPTG_23419 & 1.01740189 & 0.0217849 & large tegument protein UL36; \\
\hline PPTG_04377 & 0.94043542 & 0.03296512 & Major Facilitator Superfamily (MFS) proteins \\
\hline PPTG_05470 & 0.91187391 & 0.01702338 & SPRY domain in Ran binding proteins \\
\hline PPTG_22853 & 0.85943994 & 0.03296512 & Putative storage protein LPV \\
\hline PPTG_13013 & 0.8307265 & 0.0217849 & Cyst germination specific acidic repeat protein \\
\hline PPTG_20368 & 0.82758849 & 0.02281486 & NA \\
\hline PPTG_01588 & 0.82579718 & 0.02281486 & Tetratricopeptide repeat \\
\hline PPTG_04341 & 0.78702506 & 0.014592 & Kazal type serine protease inhibitors \\
\hline PPTG_00655 & 0.7658604 & 0.02490186 & Iron-enterobactin transporter ATP-binding protein \\
\hline PPTG_08559 & 0.76309934 & 0.03296512 & NA \\
\hline PPTG_00623 & 0.75665029 & 0.0217849 & The Phox Homology domain, a phosphoinositide binding module \\
\hline PPTG_22560 & 0.72235522 & 0.04236865 & Ricin-type beta-trefoil \\
\hline PPTG_07553 & 0.71836169 & 0.03296512 & HAM34-like putative membrane protein \\
\hline PPTG_01906 & 0.69845644 & 0.03303654 & Cytochrome P450 \\
\hline PPTG_11777 & 0.69839919 & 0.03303654 & Alpha-N-acetylglucosaminidase (NAGLU) tim-barrel domain \\
\hline PPTG_13016 & 0.68630319 & 0.03147853 & Glycosyltransferase (GlcNAc) \\
\hline PPTG_17323 & 0.66267543 & 0.03303654 & tRNA binding domain \\
\hline PPTG_15053 & 0.66097703 & 0.04910001 & NA \\
\hline PPTG_03113 & 0.65586116 & 0.03147853 & NA \\
\hline PPTG_00340 & 0.54904534 & 0.04815318 & Dynein heavy chain and region D6 of dynein motor \\
\hline Down-Regulated Gene & $\log \mathrm{FC}$ & FDR & Annotation in NCBI \\
\hline PPTG_17561 & -0.5858454 & 0.04815318 & Biotinyl_lipoyl_domains \\
\hline PPTG_12754 & -0.6407469 & 0.03613858 & $60 S$ ribosomal protein L38 \\
\hline PPTG_02651 & -0.8343073 & 0.03303654 & TLR4 regulator and MIR-interacting MSAP \\
\hline PPTG_00501 & -0.8933285 & 0.03147853 & Abhydrolase \\
\hline PPTG_21942 & -0.9296731 & 0.03842764 & Phosphate acetyltransferase \\
\hline PPTG_11197 & -1.0358966 & 0.03303654 & $\begin{array}{l}3^{\prime} \text {-phosphoadenosine } 5^{\prime} \text {-phosphosulfate sulfotransferase } \\
\text { (PAPS reductase)/FAD synthetase or related enzyme }\end{array}$ \\
\hline PPTG_08585 & -1.0629125 & 0.02281486 & Old yellow enzyme (OYE)-like FMN binding domain \\
\hline PPTG_21974 & -1.1383951 & 0.02281486 & NA \\
\hline PPTG_13205 & -1.2268529 & 0.04815318 & Elicitin \\
\hline PPTG_21937 & -1.2492039 & 0.03296512 & $\begin{array}{c}\text { START/RHO_alpha_C/PITP/Bet_v1/CoxG/CalC (SRPBCC) } \\
\text { ligand-binding domain superfamily }\end{array}$ \\
\hline PPTG_05327 & -1.2837131 & 0.03147853 & NA \\
\hline PPTG_15084 & -1.5159809 & 0.04674932 & TKL/DRK protein kinase \\
\hline PPTG_02595 & -1.5567119 & 0.03303654 & NAD(P)+-dependent aldehyde dehydrogenase superfamily \\
\hline PPTG_09275 & -1.6934963 & 0.00080536 & NADPH-dependent FMN reductase \\
\hline PPTG_18743 & -1.7231432 & 0.03661908 & NA \\
\hline PPTG_15596 & -1.7614863 & 0.02490186 & $\begin{array}{c}\text { START/RHO_alpha_C/PITP/Bet_v1/CoxG/CalC (SRPBCC) } \\
\text { ligand-binding domain superfamily }\end{array}$ \\
\hline PPTG_23779 & -1.7704877 & 0.00245828 & $\begin{array}{l}\text { NAD }(\mathrm{P}) \mathrm{H}: \mathrm{FMN} \text { oxidoreductases, oxygen-insensitive nitroreductase, } \\
\text { flavin reductase } \mathrm{P} \text {, dihydropteridine reductase, NADH oxidase or } \\
\text { NADH dehydrogenase. }\end{array}$ \\
\hline PPTG_05968 & -2.0360954 & 0.02831652 & Redox-sensitive bicupin YhaK, pirin superfamily \\
\hline PPTG_20266 & -2.1555007 & 0.0217849 & NADPH-dependent FMN reductase \\
\hline PPTG_05967 & -2.4675984 & 0.00569986 & Redox-sensitive bicupin YhaK, pirin superfamily \\
\hline PPTG_16697 & -3.3993324 & 0.04099675 & Solute carrier families 5 and 6-like \\
\hline
\end{tabular}




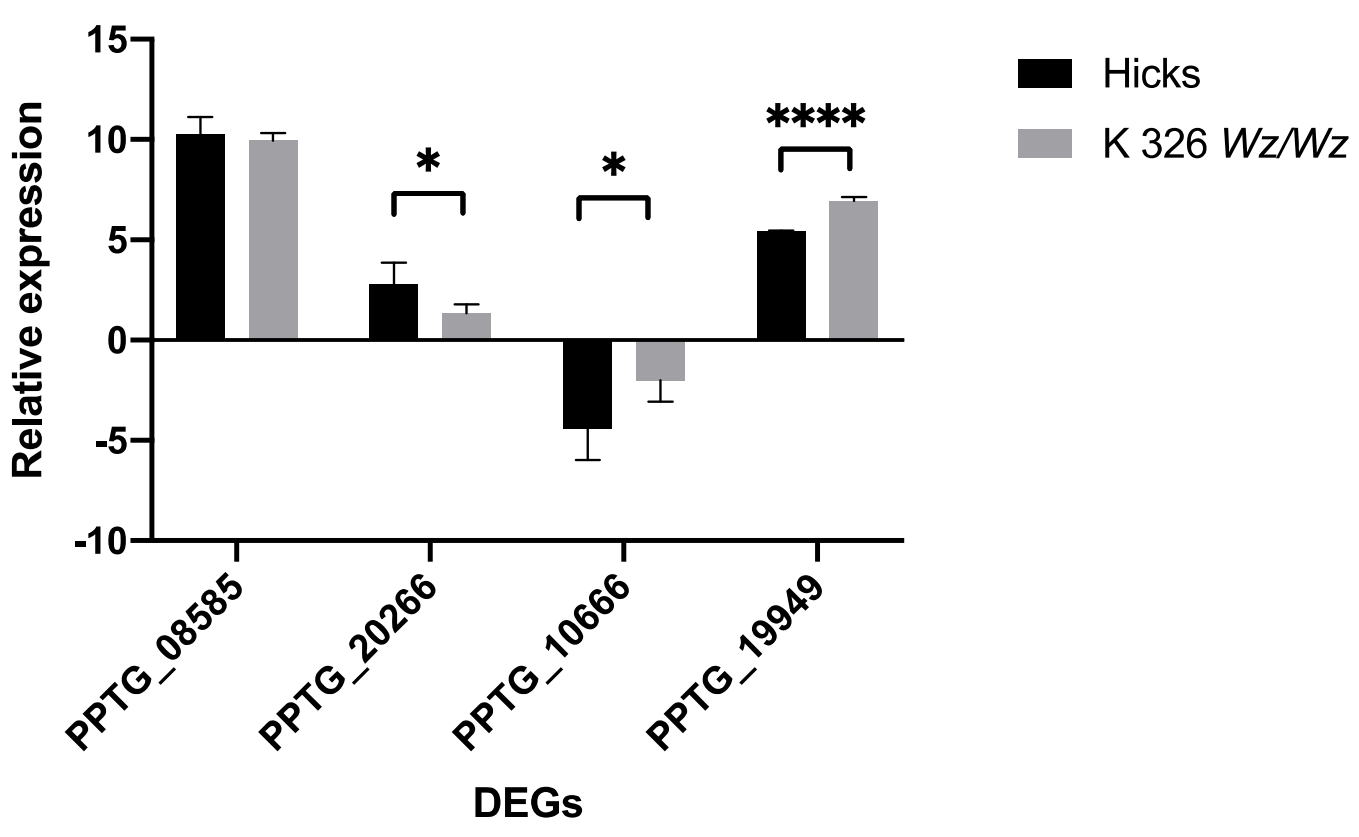

Figure 1. qRT-PCR validation of the DEGs identified in P. nicotianae by RNAseq analysis. Difference in relative gene expression between groups was determined using $t$-test in Prism 8. Significance is indicated using * for $p$ value $<0.05$, **** for $p$ value $<0.0001$. Genes PPTG_08585 and PPTG_20266 showed a lower relative expression in P. nicotianae when infecting K 326 Wz/Wz compared to infecting Hicks. Genes PPTG_10666 and PPTG_19949 showed a higher relative expression in P. nicotianae when infecting $\mathrm{K} 326 \mathrm{Wz} / \mathrm{Wz}$ compared to infecting Hicks. The expression of the genes was normalized to Ubc and WS21 as two internal controls.

\subsubsection{Over-Represented Gene Ontology Analysis}

To obtain insight into the types of differentially expressed genes in the two isolates, GO enrichment analysis was performed using BiNGO to test over-representation for the DEGs against the annotated genes in P. nicotianae. Down-regulated genes in the $\mathrm{Wz}-\mathrm{Wz}$ isolate were significantly enriched into three GO terms for the functional classes "sulfate reduction" (GO: 0019419), "sulfate assimilation, phosphoadenylyl sulfate reduction by phosphoadenylyl-sulfate reductase (thioredoxin)" (GO: 0019379) and "sulfate assimilation" (GO: 0000103). Up-regulated genes in the $\mathrm{Wz}-\mathrm{Wz}$ isolate were enriched in "monooxygenase activity" (GO: 0004497) (Figure 2). In the $\mathrm{Wz}-\mathrm{H}$ isolate, down-regulated genes were enriched into a broader spectrum of GO terms. In addition to the ones found in the $\mathrm{Wz}-\mathrm{Wz}$ isolate, down-regulated genes in the $\mathrm{Wz}-\mathrm{H}$ isolate were also enriched in "glycine cleavage complex" (GO: 0019419), "NAD(P)H dehydrogenase (quinone) activity" (GO: 0004604), "FMN binding" (GO: 0050662), and "oxidoreductase activity" (GO: 0016651, GO: 0000103, GO: 0009071; GO: 0016671). No GO terms were particularly enriched for up-regulated genes in the $\mathrm{Wz}-\mathrm{H}$ isolate (Figure 3).

\subsubsection{KEGG Analysis of DEGs}

A KEGG pathway enrichment analysis was conducted on DEGs identified in the two isolates to help understand the interaction between isolates and their adapted and non-adapted tobacco host genotypes.

For up-regulated DEGs, "spliceosome" was enriched in the $W z-W z$ isolate. No enriched pathway was identified for up-regulated DEGs in the Wz-H isolate. For downregulated DEGs, "ubiquinone and other terpenoid-quinone biosynthesis" and "biosynthesis of secondary metabolites" were enriched in the $W z-W z$ isolate. In addition to the two pathways enriched, another eight enriched pathways were identified in the $\mathrm{Wz}-\mathrm{H}$ isolate including "biosynthesis of antibiotics", "carbon metabolism", and "sulfur metabolism" (Table 5). 
(A)

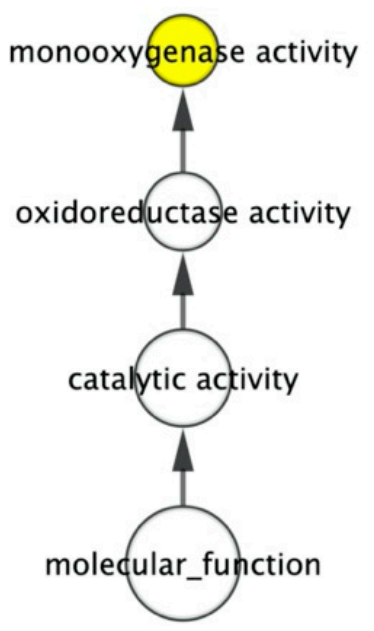

(B)

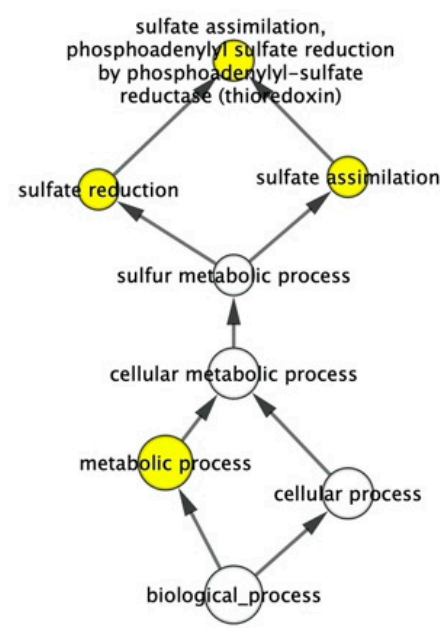

Figure 2. Enriched GO terms (colored in yellow, adjusted $p$ value $<0.05)$ for $(\mathbf{A})$ up-regulated and (B) down-regulated DEGs identified in the $W z-W z$ isolate using BiNGO.

Table 5. Enriched KEGG pathways in the $\mathrm{Wz}-\mathrm{Wz}$ and $\mathrm{Wz}-\mathrm{H}$ isolates of $P$. nicotianae on $\mathrm{K} 326 \mathrm{Wz} / \mathrm{Wz}$.

\begin{tabular}{|c|c|c|c|c|}
\hline Isolate & DEG Regulation & Term & Rich-Factor & Corrected $p$-Value \\
\hline \multirow{3}{*}{$W z-W z$} & up-regulated & Spliceosome & 0.018 & 0.049 \\
\hline & \multirow{2}{*}{ down-regulated } & Ubiquinone and other terpenoid-quinone biosynthesis & 0.118 & 0.008 \\
\hline & & Biosynthesis of secondary metabolites & 0.010 & 0.040 \\
\hline \multirow{10}{*}{$W z-\mathrm{H}$} & \multirow{10}{*}{ down-regulated } & Biosynthesis of secondary metabolites & 0.015 & 0.000 \\
\hline & & Ubiquinone and other terpenoid-quinone biosynthesis & 0.118 & 0.002 \\
\hline & & Biosynthesis of antibiotics & 0.016 & 0.002 \\
\hline & & Glyoxylate and dicarboxylate metabolism & 0.053 & 0.005 \\
\hline & & Glycine, serine and threonine metabolism & 0.051 & 0.006 \\
\hline & & Metabolic pathways & 0.005 & 0.007 \\
\hline & & Carbon metabolism & 0.014 & 0.043 \\
\hline & & Ascorbate and aldarate metabolism & 0.067 & 0.049 \\
\hline & & Sulfur metabolism & 0.059 & 0.049 \\
\hline & & Histidine metabolism & 0.056 & 0.049 \\
\hline
\end{tabular}



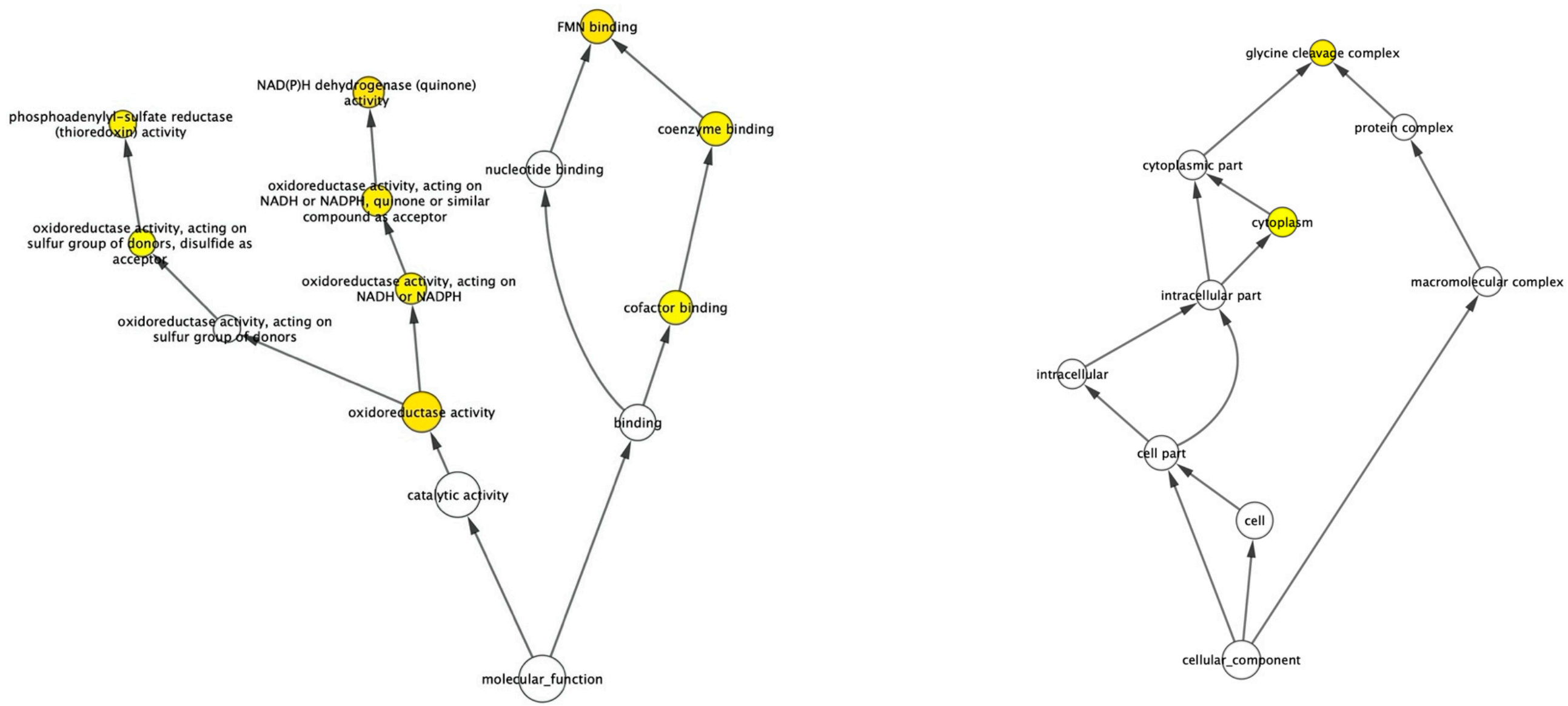

Figure 3. Cont. 


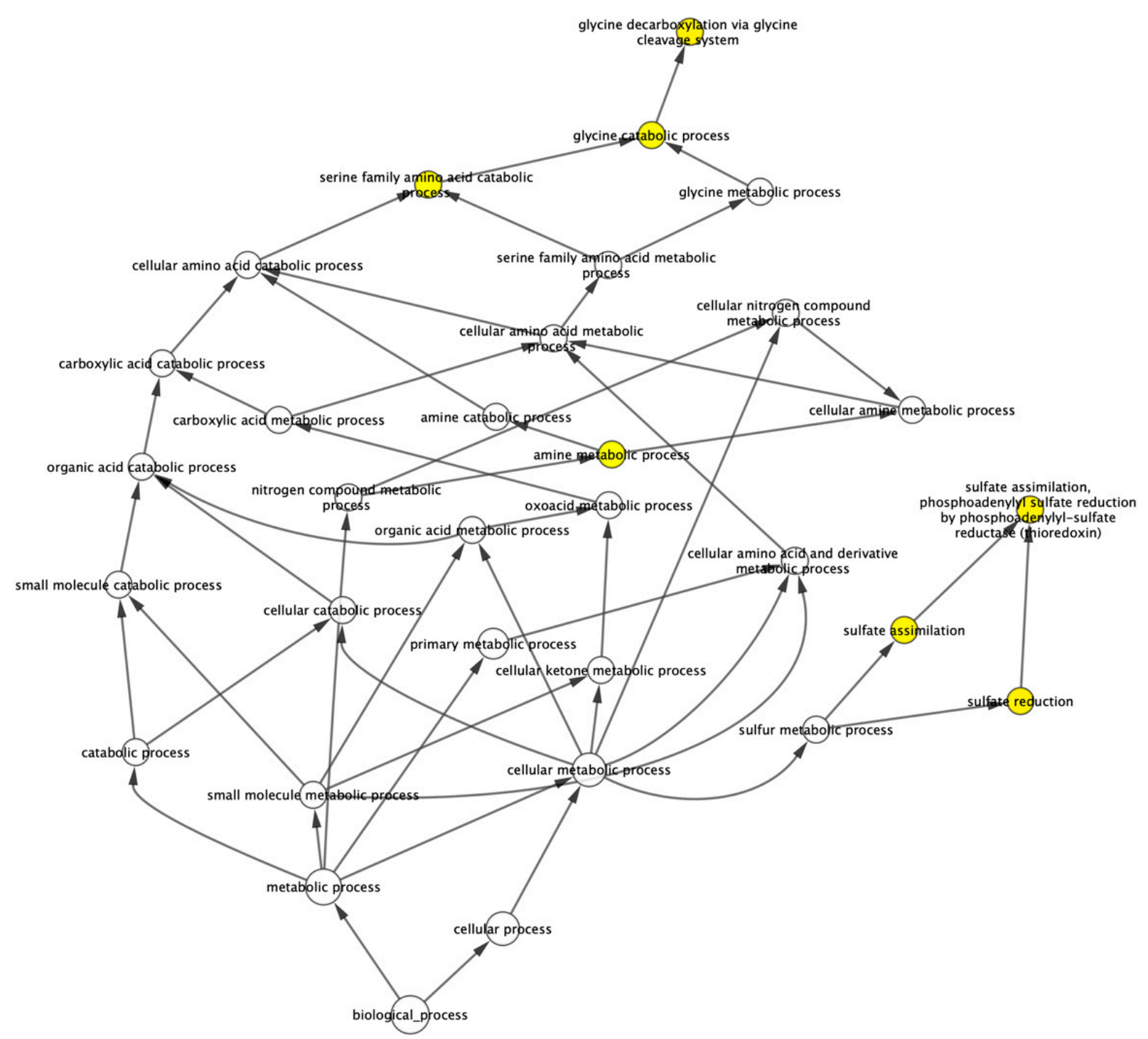

Figure 3. Enriched GO terms (colored in yellow, adjusted $p$ value $<0.05$ ) for down-regulated DEGs identified in the $W z-H$ isolate using BiNGO. 


\subsubsection{PHIB-Database Blast}

The pathogen-host interactions database (PHI-base) stores curated molecular and biological information on genes experimentally proven to alter the outcome of pathogen-host interactions. Given that a majority of the DEGs were identified to encode uncharacterized proteins in the annotated Phytophthora nicotianae genome, the protein sequences of the identified DEGs were subjected to a blast search in the PHI-base to determine their role or the role of their orthologs to have a better knowledge of how they could potentially contribute to aggressiveness in individual isolates.

Among the up-regulated genes in the $W z-W z$ isolate, $68.75 \%(11 / 16)$ were associated with pathogenicity. In contrast, $31.03 \%(9 / 29)$ of the up-regulated genes in the $\mathrm{Wz}-\mathrm{H}$ isolate were found to have a role in pathogenicity. The two isolates showed a similar percentage of down-regulated genes involved in pathogenicity, with $46.67 \%(14 / 30)$ in the $W z-W z$ isolate and $47.62 \%(10 / 21)$ in the $\mathrm{Wz}-\mathrm{H}$ isolate (Table S1).

Specifically, the $W z-W z$ isolate up regulated pathogenicity-associated genes including, but not limited to, PPTG_10595 encoding a protein belonging to ABC transporter superfamily, PPTG_12158 encoding ULK/ULK protein kinase, PPTG_02121 encoding a heat shock protein 70, and PPTG_06886 encoding a protein within solute carrier family. Down-regulated pathogenicity-associated genes included PPTG_19261 and PPTG_00236 encoding WRKY transcription factor, PPTG_02595 encoding aldehyde dehydrogenase, and PPTG_02595 encoding a sugar transport protein (Table S1).

The $\mathrm{Wz}-\mathrm{H}$ isolate up regulated pathogenicity-associated genes including PPTG_22560 which matched to a gene encoding an effector protein in P. infestans and PPTG_15982 matched to a gene encoding a glycoside hydrolase in P. palmivora. The down regulated genes in association with pathogenicity in the $\mathrm{Wz}-\mathrm{H}$ isolate included PPTG_15084 encoding a TKL/DRK protein kinase and PPTG_13205 matched to a gene encoding an elicitin-like protein in P. infestans (Table S1).

\subsubsection{Genes with Differential Transcript Usage in P. nicotianae}

Differential transcript usage allows a single gene to produce multiple transcript isoforms. To explore possible molecular mechanisms other than selectively expressing genes in a specific pathogen isolate-host genotype interaction, genes with differential transcript usage were identified and analyzed in P. nicotianae. Sixty-six and 128 annotated genes in the $\mathrm{Wz}-\mathrm{Wz}$ and $\mathrm{Wz}-\mathrm{H}$ isolates, respectively, were differentially transcribed when the given isolate was infecting $\mathrm{K} 326 \mathrm{Wz} / \mathrm{Wz}$ compared to its infecting Hicks. Intronretention (IR), alternative transcription start sites (ATSS), and alternative transcription termination sites (ATTS) were the three most common alternative splicing types in the two isolates.

Twenty-seven and 60 differentially transcribed genes were predicted to have functional consequences in the $\mathrm{Wz}-\mathrm{Wz}$ and $\mathrm{Wz}-\mathrm{H}$ isolates, respectively (Table S2). These genes were subjected to GO and PHIB blast analyses. No GO terms were enriched for either of the two sets of genes identified in the two isolates. The PHIB blast results showed that 9 out of $27(33.3 \%)$ genes with differential transcript usage in the $W z-W z$ isolate were involved in pathogenicity, while $13(21.7 \%)$ pathogenicity-associated genes were identified from the 60 genes in the $\mathrm{Wz}-\mathrm{H}$ isolate (Table S3). For example, the $\mathrm{Wz}-\mathrm{Wz}$ isolate alternatively spliced genes PPTG_10075 encoding a serine/threonine protein kinase and PPTG_00215 encoding eukaryotic translation initiation factor. The $\mathrm{Wz}-\mathrm{H}$ isolate differentially transcribed genes such as PPTG_06129 encoding pre-mRNA $3^{\prime}$ end processing protein and PPTG_03522 encoding ankyrin repeat protein.

\subsubsection{SNPs Identified in the $\mathrm{Wz}-\mathrm{Wz}$ and $\mathrm{Wz}-\mathrm{H}$ Isolates of $P$. nicotianae}

A total of 8 SNPs were identified between the two isolates of P. nicotianae (Table 6). Three SNPs (CHROM: 7000000185249344 POS: 2066387; CHROM: 7000000185249344 POS: 2066377; CHROM: 7000000185249344 POS: 2066882) were located in gene PPTG_03590 encoding a conserved hypothetical protein in Phytophthora species with unknown function. 
A SNP (CHROM: 7000000185249172 POS: 182510) was located in PPTG_17734 which encodes an effector protein in the Crinkler family. Another SNP (CHROM: 7000000185249382 POS: 599392) was found in PPTG_05817 encoding transcription factor $\mathrm{S}$.

Table 6. SNPs identified in thte $W z-W z$ and $W z-H$ isolates of $P$. nicotianae.

\begin{tabular}{|c|c|c|c|c|c|}
\hline CHROM & POS & Gene & Annotation & $W z-W z$ & $W z-H$ \\
\hline 7000000185249081 & 1188712 & PPTG_07972 & Hypothetical protein & $\mathrm{C} / \mathrm{C}$ & $\mathrm{C} / \mathrm{T}$ \\
\hline 7000000185249382 & 599392 & PPTG_05817 & Transcription factor $S$ & $\mathrm{C} / \mathrm{C}$ & $\mathrm{C} / \mathrm{T}$ \\
\hline 7000000185249084 & 546281 & PPTG_05165 & Hypothetical protein & $\mathrm{T} / \mathrm{C}$ & $\mathrm{T} / \mathrm{T}$ \\
\hline 7000000185249172 & 182510 & PPTG_17734 & Crinkler family & $\mathrm{G} / \mathrm{A}$ & $\mathrm{G} / \mathrm{G}$ \\
\hline 7000000185249344 & 2066387 & PPTG_03590 & Hypothetical protein & $\mathrm{G} / \mathrm{A}$ & $\mathrm{G} / \mathrm{G}$ \\
\hline 7000000185249061 & 1073008 & NA & NA & $\mathrm{A} / \mathrm{T}$ & $\mathrm{T} / \mathrm{T}$ \\
\hline 7000000185249344 & 2066377 & PPTG_03590 & Hypothetical protein & $\mathrm{A} / \mathrm{G}$ & $\mathrm{G} / \mathrm{G}$ \\
\hline 7000000185249344 & 2066882 & PPTG_03590 & Hypothetical protein & $\mathrm{C} / \mathrm{T}$ & $\mathrm{T} / \mathrm{T}$ \\
\hline
\end{tabular}

\subsection{Overview of DEGs in N. tabacum}

\subsubsection{DEGs Identified in N. tabacum}

DEGs were identified in $\mathrm{K} 326 \mathrm{Wz} / \mathrm{Wz}$ by comparing it to Hicks inoculated with a given P. nicotianae isolate. When inoculated with the $\mathrm{Wz}-\mathrm{Wz}$ isolate, $\mathrm{K} 326 \mathrm{Wz} / \mathrm{Wz}$ had 305 up-regulated and 303 down-regulated genes compared to 174 up-regulated and 393 down-regulated genes when inoculated with the $\mathrm{Wz}-\mathrm{H}$ isolate. The DEGs identified in $\mathrm{K} 326 \mathrm{Wz} / \mathrm{Wz}$ inoculated with the two isolates were further analyzed for commonalities and differences. There were 94 up-regulated and 163 down-regulated genes in common from samples of K $326 \mathrm{Wz} / \mathrm{Wz}$ inoculated with the two isolates (Table 7; Table S4).

Table 7. Number of DEGs identified in $\mathrm{K} 326 \mathrm{Wz} / \mathrm{Wz}$ inoculated with either the $\mathrm{Wz}-\mathrm{Wz}$ or the $\mathrm{Wz}-\mathrm{H}$ isolate of $P$. nicotianae compared to Hicks inoculated with the same isolate.

\begin{tabular}{ccccc}
\hline $\begin{array}{c}\text { Tobacco Genotype for } \\
\text { DEG Identification }\end{array}$ & Isolate for Inoculation & Total No. of DEGs & Up-Regulated DEGs & $\begin{array}{c}\text { Down-Regulated } \\
\text { DEGs }\end{array}$ \\
\hline K $326 \mathrm{Wz} / \mathrm{Wz}$ & $W z-W z$ & 608 & 305 & 303 \\
$\mathrm{~K} 326 \mathrm{Wz} / \mathrm{Wz}$ & $W z-\mathrm{H}$ & 567 & 174 & 393 \\
& Shared DEGs & 257 & 94 & 163 \\
\hline
\end{tabular}

Among the commonly up-regulated genes were Nitab4.5_0007488g0040.1 and Nitab4.5_ $0001477 \mathrm{~g} 0080.1$ that encode pathogenesis-related (PR) protein 1a. In addition, five genes, Nitab4.5_0003154g0030.1, Nitab4.5_0000754g0140.1, Nitab4.5_0003324g0100.1, Nitab4.5_ 0014015g0010.1, Nitab4.5_0013087g0020.1, were predicted to encode proteinase inhibitors. Of the 163 commonly down-regulated genes, 13 genes were found to encode Glutathione S-transferase or Glutathione S-transferase-like protein.

\subsubsection{GO Analysis of DEGs in Tobacco}

Up-regulated genes identified exclusively in $\mathrm{K} 326 \mathrm{Wz} / \mathrm{Wz}$ inoculated with the $\mathrm{Wz}-\mathrm{Wz}$ isolate were enriched in $33 \mathrm{GO}$ terms, while down-regulated genes were enriched in $63 \mathrm{GO}$ terms. The GO terms enriched for down-regulated DEGs are involved in various aspects of nuclear biosynthesis including "nucleosome organization" (GO: 0034728), "nucleosome assembly" (GO: 0006334), “chromosome organization" (GO: 0051276), "chromatin assembly or disassembly" (GO: 0006333), "DNA packaging complex" (GO: 0044815), "DNA conformation change" (GO: 0071103), "DNA-templated transcription, initiation" (GO: 0006352), "RNA biosynthetic process" (GO: 0032774), "protein complex biogenesis" (GO: 0070271), "protein complex assembly" (GO: 0006461) (Table 8).

No significant GO terms were enriched for exclusively up-regulated genes in $\mathrm{K} 326 \mathrm{Wz} / \mathrm{Wz}$ inoculated with the $\mathrm{Wz}-\mathrm{H}$ isolate, and $8 \mathrm{GO}$ terms were enriched for downregulated genes after inoculation with the $\mathrm{Wz}-\mathrm{H}$ isolate (Table 9). 
Table 8. GO terms enriched for DEGs exclusively identified in $\mathrm{K} 326 \mathrm{Wz} / \mathrm{Wz}$ inoculated with the $\mathrm{Wz}-\mathrm{Wz}$ isolate.

\begin{tabular}{|c|c|c|c|c|}
\hline \multicolumn{5}{|c|}{ Up-Regulated DEGs in $\mathrm{K} 326 \mathrm{Wz} / \mathrm{Wz}$} \\
\hline GO Accession & Term & Term Type & $p$ Value & FDR \\
\hline GO: 0044710 & single-organism metabolic process & $\mathrm{P}$ & $3.40 \times 10^{-6}$ & 0.0019 \\
\hline GO: 0044281 & small molecule metabolic process & $\mathrm{P}$ & 0.00015 & 0.0063 \\
\hline GO: 0044712 & single-organism catabolic process & $\mathrm{P}$ & 0.00015 & 0.0063 \\
\hline GO: 0046031 & ADP metabolic process & $\mathrm{P}$ & 0.00018 & 0.0063 \\
\hline GO: 0009179 & purine ribonucleoside diphosphate metabolic process & $\mathrm{P}$ & 0.00018 & 0.0063 \\
\hline GO: 0046496 & nicotinamide nucleotide metabolic process & $\mathrm{P}$ & 0.00015 & 0.0063 \\
\hline GO: 1901575 & organic substance catabolic process & $\mathrm{P}$ & 0.00013 & 0.0063 \\
\hline GO: 0051186 & cofactor metabolic process & $\mathrm{P}$ & $6.50 \times 10^{-5}$ & 0.0063 \\
\hline GO: 0044723 & single-organism carbohydrate metabolic process & $\mathrm{P}$ & 0.00016 & 0.0063 \\
\hline GO: 0006757 & ATP generation from ADP & $\mathrm{P}$ & 0.00018 & 0.0063 \\
\hline GO: 0006732 & coenzyme metabolic process & $\mathrm{P}$ & $7.40 \times 10^{-5}$ & 0.0063 \\
\hline GO: 0009135 & purine nucleoside diphosphate metabolic process & $\mathrm{P}$ & 0.00018 & 0.0063 \\
\hline GO: 0009185 & ribonucleoside diphosphate metabolic process & $\mathrm{P}$ & 0.00018 & 0.0063 \\
\hline GO: 0072524 & pyridine-containing compound metabolic process & $\mathrm{P}$ & 0.00017 & 0.0063 \\
\hline GO: 0006096 & glycolytic process & $\mathrm{P}$ & 0.00018 & 0.0063 \\
\hline GO: 0019362 & pyridine nucleotide metabolic process & $\mathrm{P}$ & 0.00015 & 0.0063 \\
\hline GO: 0006733 & oxidoreduction coenzyme metabolic process & $\mathrm{P}$ & 0.00019 & 0.0063 \\
\hline GO: 0044724 & single-organism carbohydrate catabolic process & $\mathrm{P}$ & 0.00026 & 0.0075 \\
\hline GO: 0009056 & catabolic process & $\mathrm{P}$ & 0.00025 & 0.0075 \\
\hline GO: 0006090 & pyruvate metabolic process & $\mathrm{P}$ & 0.00029 & 0.0082 \\
\hline GO: 0006165 & nucleoside diphosphate phosphorylation & $\mathrm{P}$ & 0.00032 & 0.0086 \\
\hline GO: 0009132 & nucleoside diphosphate metabolic process & $\mathrm{P}$ & 0.00042 & 0.011 \\
\hline GO: 0016209 & antioxidant activity & $\mathrm{F}$ & $8.40 \times 10^{-5}$ & 0.011 \\
\hline GO: 0003824 & catalytic activity & $\mathrm{F}$ & $8.50 \times 10^{-5}$ & 0.011 \\
\hline GO: 0046939 & nucleotide phosphorylation & $\mathrm{P}$ & 0.00053 & 0.012 \\
\hline GO: 0005975 & carbohydrate metabolic process & $\mathrm{P}$ & 0.00053 & 0.012 \\
\hline GO: 0016052 & carbohydrate catabolic process & $\mathrm{P}$ & 0.00056 & 0.012 \\
\hline GO: 0016903 & $\begin{array}{l}\text { oxidoreductase activity, acting on the aldehyde or oxo group } \\
\text { of donors }\end{array}$ & $\mathrm{F}$ & 0.00017 & 0.014 \\
\hline GO: 0006082 & organic acid metabolic process & $\mathrm{P}$ & 0.0014 & 0.03 \\
\hline GO: 0043436 & oxoacid metabolic process & $\mathrm{P}$ & 0.0016 & 0.033 \\
\hline GO: 0019752 & carboxylic acid metabolic process & $\mathrm{P}$ & 0.0016 & 0.033 \\
\hline GO: 0043168 & anion binding & $\mathrm{F}$ & 0.00057 & 0.035 \\
\hline GO: 1901135 & carbohydrate derivative metabolic process & $\mathrm{P}$ & 0.0025 & 0.048 \\
\hline \multicolumn{5}{|c|}{ Down-Regulated DEGs in K326 Wz/Wz } \\
\hline GO Accession & Term & Term Type & $p$ Value & FDR \\
\hline GO: 0000786 & nucleosome & $\mathrm{C}$ & $5.10 \times 10^{-27}$ & $2.10 \times 10^{-25}$ \\
\hline GO: 0032993 & protein-DNA complex & $\mathrm{C}$ & $5.10 \times 10^{-27}$ & $2.10 \times 10^{-25}$ \\
\hline GO: 0044815 & DNA packaging complex & $\mathrm{C}$ & $8.30 \times 10^{-27}$ & $2.20 \times 10^{-25}$ \\
\hline GO: 0000785 & chromatin & $\mathrm{C}$ & $3.40 \times 10^{-26}$ & $6.90 \times 10^{-25}$ \\
\hline GO: 0046982 & protein heterodimerization activity & $\mathrm{F}$ & $1.60 \times 10^{-26}$ & $2.40 \times 10^{-24}$ \\
\hline GO: 0031497 & chromatin assembly & $\mathrm{P}$ & $5.30 \times 10^{-26}$ & $7.70 \times 10^{-24}$ \\
\hline GO: 0065004 & protein-DNA complex assembly & $\mathrm{P}$ & $8.30 \times 10^{-26}$ & $7.70 \times 10^{-24}$ \\
\hline GO: 0034728 & nucleosome organization & $\mathrm{P}$ & $5.30 \times 10^{-26}$ & $7.70 \times 10^{-24}$ \\
\hline GO: 0006334 & nucleosome assembly & $\mathrm{P}$ & $5.30 \times 10^{-26}$ & $7.70 \times 10^{-24}$ \\
\hline GO: 0071824 & protein-DNA complex subunit organization & $\mathrm{P}$ & $8.30 \times 10^{-26}$ & $7.70 \times 10^{-24}$ \\
\hline GO: 0006333 & chromatin assembly or disassembly & $\mathrm{P}$ & $1.10 \times 10^{-25}$ & $8.80 \times 10^{-24}$ \\
\hline GO: 0006323 & DNA packaging & $\mathrm{P}$ & $1.70 \times 10^{-25}$ & $1.20 \times 10^{-23}$ \\
\hline GO: 0071103 & DNA conformation change & $\mathrm{P}$ & $2.60 \times 10^{-24}$ & $1.50 \times 10^{-22}$ \\
\hline GO: 0044427 & chromosomal part & $\mathrm{C}$ & $1.00 \times 10^{-23}$ & $1.70 \times 10^{-22}$ \\
\hline GO: 0005694 & chromosome & $\mathrm{C}$ & $1.90 \times 10^{-22}$ & $2.50 \times 10^{-21}$ \\
\hline GO: 0006325 & chromatin organization & $\mathrm{P}$ & $7.90 \times 10^{-23}$ & $4.10 \times 10^{-21}$ \\
\hline GO: 0034622 & cellular macromolecular complex assembly & $\mathrm{P}$ & $4.30 \times 10^{-21}$ & $2.00 \times 10^{-19}$ \\
\hline GO: 0051276 & chromosome organization & $\mathrm{P}$ & $1.00 \times 10^{-20}$ & $4.20 \times 10^{-19}$ \\
\hline GO: 0065003 & macromolecular complex assembly & $\mathrm{P}$ & $1.30 \times 10^{-20}$ & $5.00 \times 10^{-19}$ \\
\hline GO: 0070271 & protein complex biogenesis & $\mathrm{P}$ & $8.40 \times 10^{-20}$ & $2.80 \times 10^{-18}$ \\
\hline
\end{tabular}


Table 8. Cont.

\begin{tabular}{|c|c|c|c|c|}
\hline \multicolumn{5}{|c|}{ Up-Regulated DEGs in $\mathrm{K} 326 \mathrm{Wz} / \mathrm{Wz}$} \\
\hline GO Accession & Term & Term Type & $p$ Value & FDR \\
\hline GO: 0006461 & protein complex assembly & $\mathrm{P}$ & $8.40 \times 10^{-20}$ & $2.80 \times 10^{-18}$ \\
\hline GO: 0022607 & cellular component assembly & $\mathrm{P}$ & $4.90 \times 10^{-19}$ & $1.50 \times 10^{-17}$ \\
\hline GO: 0071822 & protein complex subunit organization & $\mathrm{P}$ & $1.40 \times 10^{-18}$ & $3.90 \times 10^{-17}$ \\
\hline GO: 0043933 & macromolecular complex subunit organization & $\mathrm{P}$ & $4.60 \times 10^{-18}$ & $1.20 \times 10^{-16}$ \\
\hline GO: 0044085 & cellular component biogenesis & $\mathrm{P}$ & $3.80 \times 10^{-17}$ & $9.70 \times 10^{-16}$ \\
\hline GO: 0006996 & organelle organization & $\mathrm{P}$ & $5.30 \times 10^{-17}$ & $1.30 \times 10^{-15}$ \\
\hline GO: 0046983 & protein dimerization activity & $\mathrm{F}$ & $1.70 \times 10^{-13}$ & $1.30 \times 10^{-11}$ \\
\hline GO: 0016043 & cellular component organization & $\mathrm{P}$ & $5.30 \times 10^{-12}$ & $1.20 \times 10^{-10}$ \\
\hline GO: 0071840 & cellular component organization or biogenesis & $\mathrm{P}$ & $3.10 \times 10^{-11}$ & $6.90 \times 10^{-10}$ \\
\hline GO: 0044422 & organelle part & $\mathrm{C}$ & $2.30 \times 10^{-10}$ & $2.30 \times 10^{-9}$ \\
\hline GO: 0044446 & intracellular organelle part & $\mathrm{C}$ & $2.30 \times 10^{-10}$ & $2.30 \times 10^{-9}$ \\
\hline GO: 0003677 & DNA binding & $\mathrm{F}$ & $5.50 \times 10^{-11}$ & $2.80 \times 10^{-9}$ \\
\hline GO: 0043234 & protein complex & $\mathrm{C}$ & $4.90 \times 10^{-9}$ & $4.50 \times 10^{-8}$ \\
\hline GO: 0043232 & intracellular non-membrane-bounded organelle & $\mathrm{C}$ & $1.30 \times 10^{-8}$ & $9.40 \times 10^{-8}$ \\
\hline GO: 0043228 & non-membrane-bounded organelle & $\mathrm{C}$ & $1.30 \times 10^{-8}$ & $9.40 \times 10^{-8}$ \\
\hline GO: 0005634 & nucleus & $\mathrm{C}$ & $3.00 \times 10^{-6}$ & $2.00 \times 10^{-5}$ \\
\hline GO: 0009987 & cellular process & $\mathrm{P}$ & $2.10 \times 10^{-6}$ & $4.30 \times 10^{-5}$ \\
\hline GO: 0003676 & nucleic acid binding & $\mathrm{F}$ & $1.30 \times 10^{-6}$ & $5.10 \times 10^{-5}$ \\
\hline GO: 0032991 & macromolecular complex & $\mathrm{C}$ & $8.20 \times 10^{-6}$ & $5.10 \times 10^{-5}$ \\
\hline GO: 0006352 & DNA-templated transcription, initiation & $\mathrm{P}$ & $6.00 \times 10^{-6}$ & 0.00012 \\
\hline GO: 0043231 & intracellular membrane-bounded organelle & $\mathrm{C}$ & 0.0002 & 0.0011 \\
\hline GO: 0043227 & membrane-bounded organelle & $\mathrm{C}$ & 0.0002 & 0.0011 \\
\hline GO: 0043229 & intracellular organelle & $\mathrm{C}$ & 0.00071 & 0.0034 \\
\hline GO: 0043226 & organelle & $\mathrm{C}$ & 0.00071 & 0.0034 \\
\hline GO: 1901576 & organic substance biosynthetic process & $\mathrm{P}$ & 0.00025 & 0.0046 \\
\hline GO: 0009058 & biosynthetic process & $\mathrm{P}$ & 0.00025 & 0.0046 \\
\hline GO: 1901363 & heterocyclic compound binding & $\mathrm{F}$ & 0.00019 & 0.005 \\
\hline GO: 0097159 & organic cyclic compound binding & $\mathrm{F}$ & 0.00019 & 0.005 \\
\hline GO: 0019438 & aromatic compound biosynthetic process & $\mathrm{P}$ & 0.00045 & 0.008 \\
\hline GO: 1901362 & organic cyclic compound biosynthetic process & $\mathrm{P}$ & 0.0006 & 0.009 \\
\hline GO: 0097659 & nucleic acid-templated transcription & $\mathrm{P}$ & 0.00059 & 0.009 \\
\hline GO: 0006351 & transcription, DNA-templated & $\mathrm{P}$ & 0.00059 & 0.009 \\
\hline GO: 0032774 & RNA biosynthetic process & $\mathrm{P}$ & 0.0006 & 0.009 \\
\hline GO: 0044249 & cellular biosynthetic process & $\mathrm{P}$ & 0.00057 & 0.009 \\
\hline GO: 0034654 & nucleobase-containing compound biosynthetic process & $\mathrm{P}$ & 0.0018 & 0.027 \\
\hline GO: 0044424 & intracellular part & $\mathrm{C}$ & 0.0061 & 0.028 \\
\hline GO: 0065007 & biological regulation & $\mathrm{P}$ & 0.0024 & 0.034 \\
\hline GO: 0050794 & regulation of cellular process & $\mathrm{P}$ & 0.0025 & 0.034 \\
\hline GO: 0005622 & intracellular & $\mathrm{C}$ & 0.0081 & 0.035 \\
\hline GO: 0044711 & single-organism biosynthetic process & $\mathrm{P}$ & 0.0029 & 0.039 \\
\hline GO: 0050789 & regulation of biological process & $\mathrm{P}$ & 0.0031 & 0.04 \\
\hline GO: 0065008 & regulation of biological quality & $\mathrm{P}$ & 0.0034 & 0.042 \\
\hline GO: 0018130 & heterocycle biosynthetic process & $\mathrm{P}$ & 0.0036 & 0.043 \\
\hline
\end{tabular}

Table 9. GO terms enriched for DEGs exclusively identified in $\mathrm{K} 326 \mathrm{Wz} / \mathrm{Wz}$ inoculated with the $\mathrm{Wz}-\mathrm{H}$ isolate.

\begin{tabular}{|c|c|c|c|c|}
\hline \multicolumn{5}{|c|}{ Down-Regulated DEGs in K326 Wz/Wz } \\
\hline GO Accession & Term & Term Type & $p$ Value & FDR \\
\hline GO: 0006457 & protein folding & $\mathrm{P}$ & $9.70 \times 10^{-11}$ & $3.60 \times 10^{-8}$ \\
\hline GO: 0051082 & unfolded protein binding & $\mathrm{F}$ & $1.30 \times 10^{-9}$ & $2.90 \times 10^{-7}$ \\
\hline GO: 0005488 & binding & $\mathrm{F}$ & $2.30 \times 10^{-5}$ & 0.0025 \\
\hline GO: 0043565 & sequence-specific DNA binding & $\mathrm{F}$ & 0.00035 & 0.026 \\
\hline GO: 1901363 & heterocyclic compound binding & $\mathrm{F}$ & 0.0011 & 0.048 \\
\hline GO: 0001071 & nucleic acid binding transcription factor activity & $\mathrm{F}$ & 0.0015 & 0.048 \\
\hline GO: 0097159 & organic cyclic compound binding & $\mathrm{F}$ & 0.0011 & 0.048 \\
\hline GO: 0003700 & transcription factor activity, sequence-specific DNA binding & $\mathrm{F}$ & 0.0015 & 0.048 \\
\hline
\end{tabular}


To investigate the potential resistance mechanism in $\mathrm{K} 326 \mathrm{Wz} / \mathrm{Wz}$, commonly upregulated and down-regulated DEGs found across samples of $\mathrm{K} 326 \mathrm{Wz} / \mathrm{Wz}$ inoculated with each of the two isolates were analyzed for enriched GO terms. In particular, GO terms in the functional categories "serine-type endopeptidase inhibitor activity" (GO: 0004867), "peptidase inhibitor activity" (GO: 0030414), "peptidase regulator activity" (GO: 0061134), "endopeptidase inhibitor activity" (GO: 0004866), "endopeptidase regulator activity" (GO: 0061135) were enriched for the up-regulated genes (Table 10). GO terms enriched for the down-regulated genes in the functional categories included "transferase activity, transferring hexosyl groups" (GO: 0016758), "transferase activity, transferring glycosyl groups" (GO: 0016757), "ATPase activity, coupled to transmembrane movement of substances" (GO: 0042626), "ATPase activity, coupled to movement of substances" (GO: 0043492), "ATPase activity" (GO: 0016887), "ATPase activity, coupled" (GO: 0042623) (Table 10).

Table 10. GO terms enriched for DEGs identified in $\mathrm{K} 326 \mathrm{Wz} / W z$ across inoculations using the $W z-W z$ and $W z-\mathrm{H}$ isolates.

\begin{tabular}{|c|c|c|c|c|}
\hline \multicolumn{5}{|c|}{ GO Terms Enriched for Up-Regulated DEGs in K326 Wz/Wz } \\
\hline GO Accession & Term & Term Type & $p$ Value & FDR \\
\hline GO: 0004867 & serine-type endopeptidase inhibitor activity & $\mathrm{F}$ & $2.60 \times 10^{-11}$ & $4.20 \times 10^{-9}$ \\
\hline GO: 0030414 & peptidase inhibitor activity & $\mathrm{F}$ & $1.40 \times 10^{-8}$ & $4.40 \times 10^{-7}$ \\
\hline GO: 0061134 & peptidase regulator activity & $\mathrm{F}$ & $1.40 \times 10^{-8}$ & $4.40 \times 10^{-7}$ \\
\hline GO: 0004866 & endopeptidase inhibitor activity & $\mathrm{F}$ & $1.40 \times 10^{-8}$ & $4.40 \times 10^{-7}$ \\
\hline GO: 0061135 & endopeptidase regulator activity & $\mathrm{F}$ & $1.40 \times 10^{-8}$ & $4.40 \times 10^{-7}$ \\
\hline GO: 0044710 & single-organism metabolic process & $\mathrm{P}$ & $2.10 \times 10^{-6}$ & 0.00012 \\
\hline GO: 0004857 & enzyme inhibitor activity & $\mathrm{F}$ & $1.30 \times 10^{-5}$ & 0.00036 \\
\hline GO: 0050660 & flavin adenine dinucleotide binding & $\mathrm{F}$ & $8.80 \times 10^{-5}$ & 0.0018 \\
\hline GO: 0030234 & enzyme regulator activity & $\mathrm{F}$ & $7.70 \times 10^{-5}$ & 0.0018 \\
\hline GO: 0098772 & molecular function regulator & $\mathrm{F}$ & 0.00014 & 0.0025 \\
\hline GO: 0044699 & single-organism process & $\mathrm{P}$ & 0.00015 & 0.0043 \\
\hline GO: 0016491 & oxidoreductase activity & $\mathrm{F}$ & 0.00035 & 0.0057 \\
\hline GO: 0055114 & oxidation-reduction process & $\mathrm{P}$ & 0.00032 & 0.0063 \\
\hline GO: 0050662 & coenzyme binding & $\mathrm{F}$ & 0.00085 & 0.012 \\
\hline GO: 0048037 & cofactor binding & $\mathrm{F}$ & 0.0021 & 0.029 \\
\hline \multicolumn{5}{|c|}{ GO Terms Enriched for Down-Regulated DEGs in K326 Wz/Wz } \\
\hline GO Accession & Term & Term Type & $p$ Value & FDR \\
\hline GO: 0016758 & transferase activity, transferring hexosyl groups & $\mathrm{F}$ & $3.9 \times 10^{-5}$ & 0.01 \\
\hline GO: 0016757 & transferase activity, transferring glycosyl groups & $\mathrm{F}$ & 0.00029 & 0.013 \\
\hline GO: 0015405 & P-P-bond-hydrolysis-driven transmembrane transporter activity & $\mathrm{F}$ & 0.00043 & 0.013 \\
\hline GO: 0042626 & $\begin{array}{l}\text { ATPase activity, coupled to transmembrane movement } \\
\text { of substances }\end{array}$ & $\mathrm{F}$ & 0.00021 & 0.013 \\
\hline GO: 0015399 & primary active transmembrane transporter activity & $\mathrm{F}$ & 0.00043 & 0.013 \\
\hline GO: 0043492 & ATPase activity, coupled to movement of substances & $\mathrm{F}$ & 0.00023 & 0.013 \\
\hline GO: 0016491 & oxidoreductase activity & $\mathrm{F}$ & 0.00048 & 0.013 \\
\hline GO: 0016820 & $\begin{array}{l}\text { hydrolase activity, acting on acid anhydrides, } \\
\text { catalyzing transmembrane movement of substances }\end{array}$ & $\mathrm{F}$ & 0.00042 & 0.013 \\
\hline GO: 0016667 & oxidoreductase activity, acting on a sulfur group of donors & $\mathrm{F}$ & 0.00036 & 0.013 \\
\hline GO: 0016887 & ATPase activity & $\mathrm{F}$ & 0.00073 & 0.018 \\
\hline GO: 0006457 & protein folding & $\mathrm{P}$ & 0.00031 & 0.032 \\
\hline GO: 0042592 & homeostatic process & $\mathrm{P}$ & 0.0004 & 0.032 \\
\hline GO: 0019725 & cellular homeostasis & $\mathrm{P}$ & 0.00022 & 0.032 \\
\hline GO: 0045454 & cell redox homeostasis & $\mathrm{P}$ & 0.00017 & 0.032 \\
\hline GO: 0042623 & ATPase activity, coupled & $\mathrm{F}$ & 0.0021 & 0.048 \\
\hline
\end{tabular}

\subsubsection{KEGG Pathway Enrichment Analysis of DEGs}

DEGs were subjected to KEGG pathway enrichment analysis to identify their biological roles in $\mathrm{K} 326 \mathrm{Wz} / \mathrm{Wz}$ in response to the two P. nicotianae isolates. Up-regulated DEGs in the $\mathrm{Wz}-\mathrm{Wz}$ - and $\mathrm{Wz}-\mathrm{H}$-inoculated samples were enriched in 35 and 18 KEGG 
pathways, respectively (Figures 4 and 5). Sixteen KEGG pathways were commonly enriched for up-regulated DEGs identified in $\mathrm{K} 326 \mathrm{Wz} / \mathrm{Wz}$ inoculated with each of the two isolates, with the most significantly enriched pathway being "valine, leucine and isoleucine degradation" in both $\mathrm{Wz}-\mathrm{Wz}$ - and $\mathrm{Wz}$-H-inoculated samples. Down-regulated DEGs in the $\mathrm{Wz}-\mathrm{Wz}$ - and $\mathrm{Wz}$-H-inoculated samples were enriched in 9 and 12 KEGG pathways, respectively (Figures 6 and 7). KEGG pathways that included "sulfur metabolism", "metabolic pathways", "glutathione metabolism", "ascorbate and aldarate metabolism", and "ABC transporters" were commonly enriched for down-regulated DEGs in K $326 \mathrm{Wz} / \mathrm{Wz}$ inoculated with each of the two isolates.

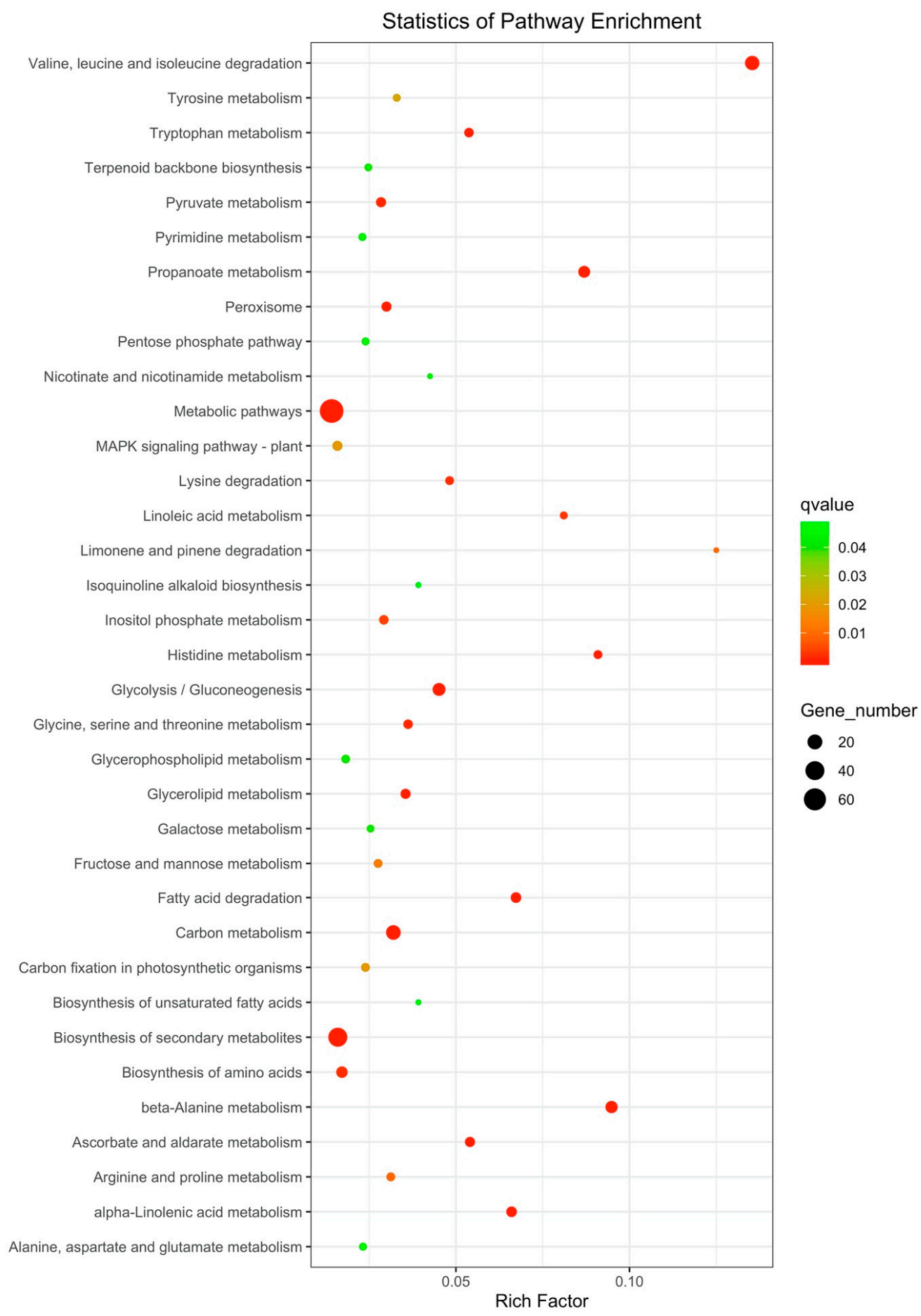

Figure 4. KEGG pathways enriched for up-regulated DEGs in $\mathrm{K} 326 \mathrm{Wz} / \mathrm{Wz}$ inoculated with the $\mathrm{Wz}-\mathrm{Wz}$ isolate of $P$. nicotianae compared to inoculated Hicks. The $y$-axis indicates the name of the KEGG pathway. The dot size means the gene number. The dot color indicates the $q$-value. 


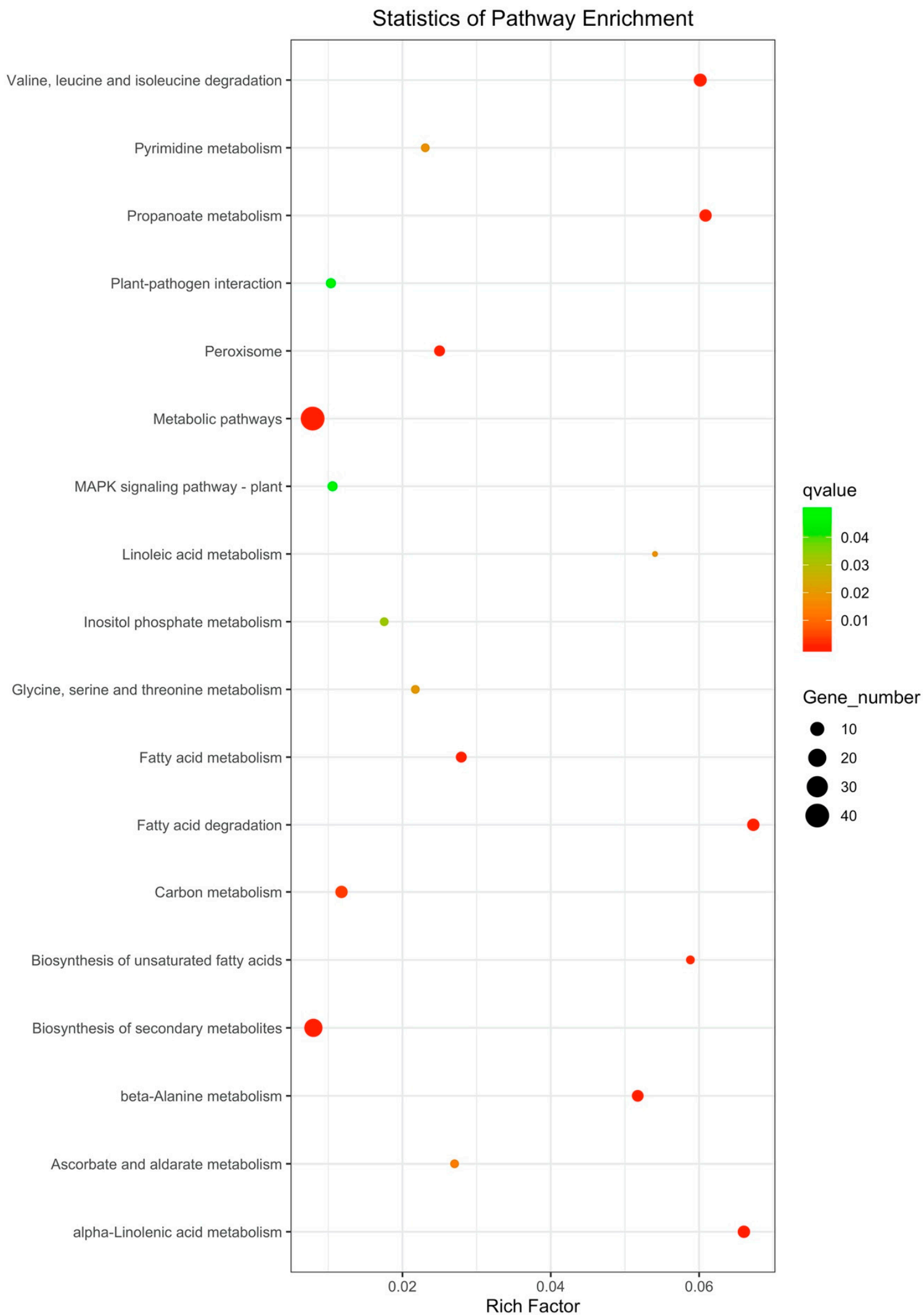

Figure 5. KEGG pathways enriched for up-regulated DEGs in $\mathrm{K} 326 \mathrm{Wz} / \mathrm{Wz}$ inoculated with the Wz-H isolate of $P$. nicotianae compared to inoculated Hicks. The $y$-axis indicates the name of the KEGG pathway. The dot size means the gene number. The dot color indicates the $q$-value. 


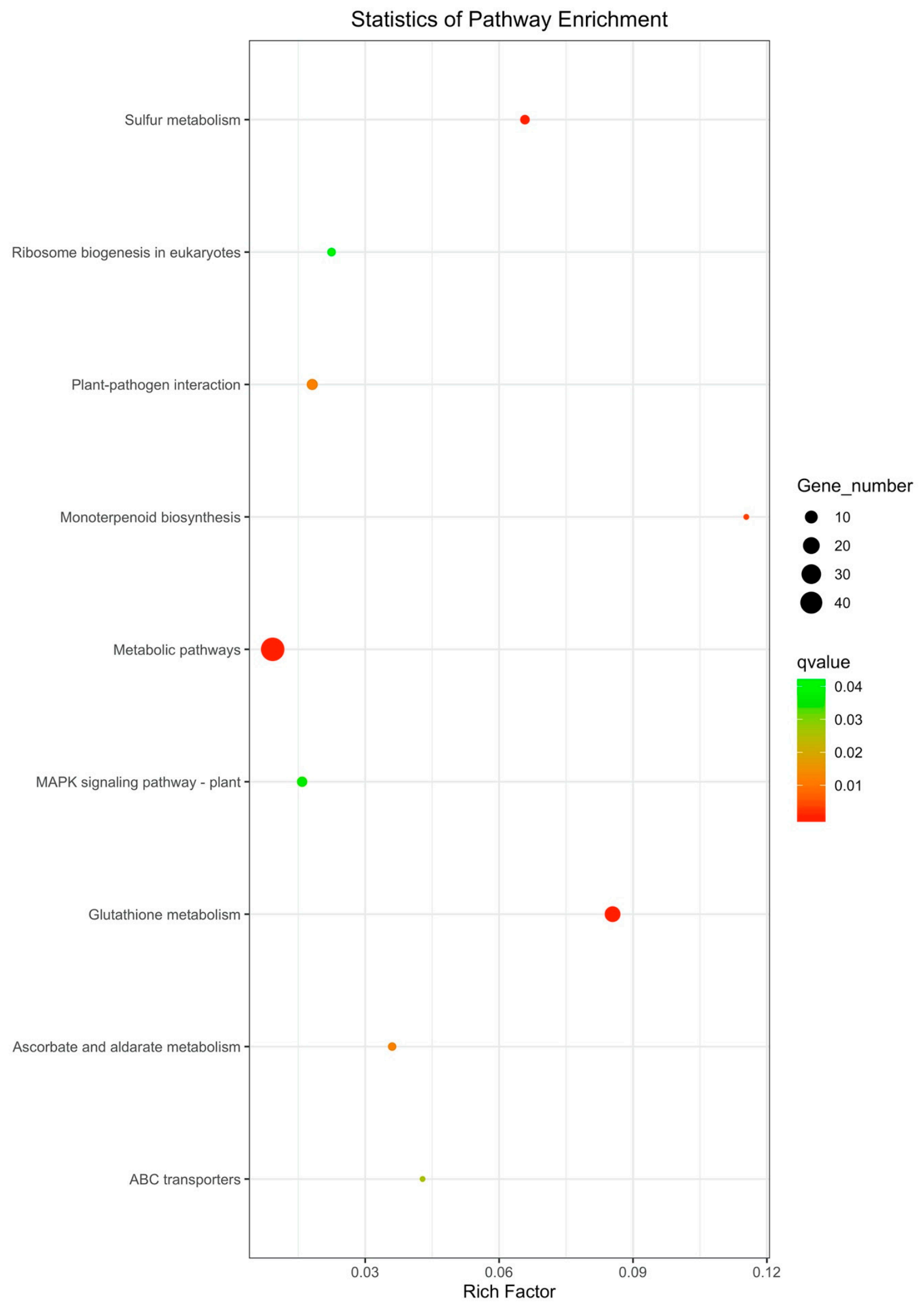

Figure 6. KEGG pathways enriched for down-regulated DEGs in $\mathrm{K} 326 \mathrm{Wz} / \mathrm{Wz}$ inoculated with the $\mathrm{Wz}-\mathrm{Wz}$ isolate of P. nicotianae compared to inoculated Hicks. The $y$-axis indicates the name of the KEGG pathway. The dot size means the gene number. The dot color indicates the $q$-value. 


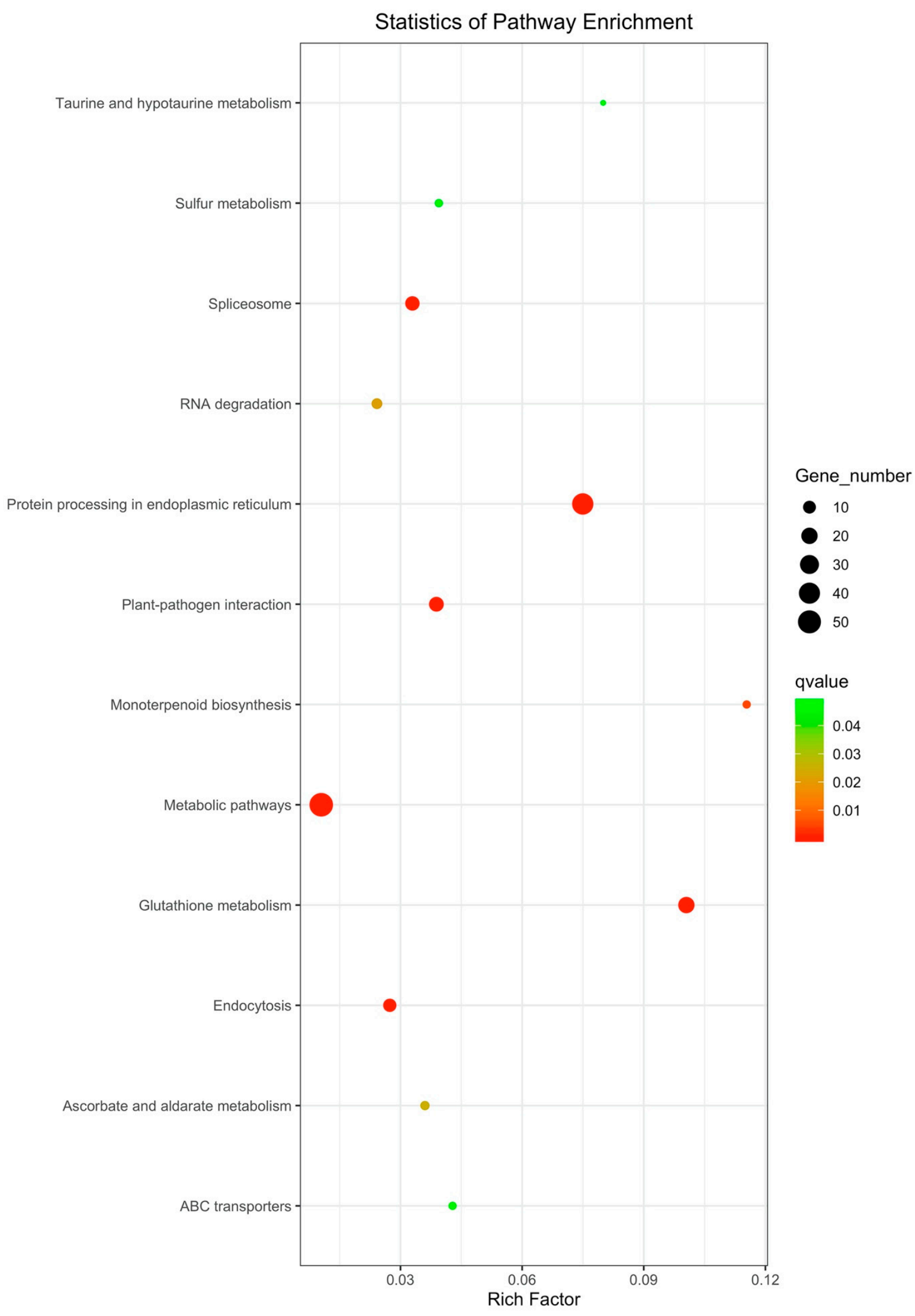

Figure 7. KEGG pathways enriched for down-regulated DEGs in $\mathrm{K} 326 \mathrm{Wz} / \mathrm{Wz}$ inoculated with the $\mathrm{Wz}-\mathrm{H}$ isolate of P. nicotianae compared to inoculated Hicks. The $y$-axis indicates the name of the KEGG pathway. The dot size means the gene number. The dot color indicates the $q$-value. 


\section{Discussion}

Black shank is one of the most devastating tobacco diseases globally. The use of host resistance is the most important and effective way to manage the disease worldwide, but with reduced value of complete resistance, an integrated approach using partial resistance is needed to effectively manage the disease [10]. Partial resistance is vital to the management of black shank, like many other root diseases, due to the absence of complete resistance genes or the loss of complete resistance due to pathogen new race development. Pathogen adaptation to partial resistance has been observed in various pathosystems, including P. nicotianae and tobacco, resulting in a pathogen population that is more aggressive than wild type populations [12-14]. It is urgent to better understand how pathogens overcome partial resistance in host plants so that resistance deployment strategies can be optimized to preserve the durability of the resistance.

The major goal of this study was to explore the molecular mechanisms underlying adaptation by P. nicotianae to partial resistance in tobacco $[14,15]$. Adaptation to partial resistance involves many genes and is generally considered to be more complex than overcoming complete resistance, which can result from a single nucleotide mutation in an Avr gene [34]. To obtain a holistic view of genetic differences that occur during adaptation to partial resistance and between pathogen isolates with distinctly different aggressiveness levels on a single source of partial resistance, we kept DEGs with a false FDR $<0.05$ without a specified fold change of gene expression. Aggressiveness and partial resistance are two quantitative traits involving various biological activities supported by a broad spectrum of genes in the pathogen and host plant. The cumulative effect of slight changes in multiple genes could potentially influence the outcome of the interaction between a specific pathogen isolate and host genotype.

The DEGs detected involve a broad spectrum of biological activities related to pathogenicity factors in P. nicotianae. The PHIB blast showed a much higher percentage $(68.75 \%)$ of up-regulated DEGs involved in pathogenicity of the $\mathrm{Wz}-\mathrm{Wz}$ isolate compared to the $\mathrm{Wz}-\mathrm{H}$ isolate $(31.03 \%)$, indicating that the $\mathrm{Wz}-\mathrm{Wz}$ isolate more efficiently recruited pathogenicity-associated genes when infecting partially resistant K $326 \mathrm{Wz} / \mathrm{Wz}$. Particularly, some genes with essential roles in pathogenicity were only found up-regulated in the $W z-W z$ isolate. These genes included PPTG_10595 that encodes a protein belonging to the ABC transporter superfamily, and PPTG_12158 that encodes ULK/ULK, a protein kinase, which has an important role in autophagy.

ABC transporters, also known as ATP Binding Cassette transporters, are of significant importance in regulating ion transport, chromosome condensation and DNA repair, mRNA processing in eukaryotes [35]. Studies have demonstrated ABC transporters are also involved in virulence [36] and toxicant efflux [37,38] in plant pathogenic fungi. It was speculated that $\mathrm{ABC}$ transporters export toxic phytoalexins in pathogens, therefore, contributing to pathogenicity. Comparing to $P$. infestans, $\mathrm{ABC}$ transporter gene family in $P$. nicotianae was significantly expanded, which suggested their crucial roles in evolutionary host adaptation [39]. The specific function of PPTG_10595 remains unclear, and given its versatility in biological processes, it is likely a higher expression of this gene could contribute to a higher aggressiveness in P. nicotianae.

ULK/ULK protein kinase (autophagy related protein 1, Atg1) is localized at the autophagy initiation site and initiates autophagy, which is critical in cell differentiation, secondary metabolism, and programmed cell death in eukaryotes [40]. In plant pathogens, autophagy has a vital role in pathogenicity. Silencing of Atg1 highly reduced conidiation and led to a reduction or loss of pathogenicity in Magnaporthe oryzae [41], Botrytis cinerea [42], Fusarium graminearum [43]. In P. sojae, expression of multiple autophagy related protein genes was increased during infection, and autophagy was highly induced during sporangium formation and cyst germination. Silencing autophagy related genes in P. sojae significantly reduced sporulation and pathogenicity, and in some cases led to defective haustorium formation, suggesting a central role of autophagy in both the development and pathogenicity in P. sojae [44]. Little is known of Atg1 in P. nicotianae, but it is possible 
that the up-regulated Atg1 expression in the $W z-W z$ isolate could be a major contributor to aggressiveness on the resistant host $\mathrm{K} 326 \mathrm{Wz} / \mathrm{Wz}$.

Three significantly enriched GO terms were assigned to down-regulated genes and one to up-regulated genes in the $W z-W z$ isolate. Sixteen enriched GO terms were attributed to down-regulated genes in $\mathrm{Wz}-\mathrm{H}$ isolate, however, no enriched $\mathrm{GO}$ terms were linked to up-regulated genes. These observations indicate that a broader spectrum of biological functions were affected because of the down-regulation of the genes in the $W z-\mathrm{H}$ isolate.

The three enriched GO terms, "sulfate reduction" (GO: 0019419), "sulfate assimilation, phosphoadenylyl sulfate reduction by phosphoadenylyl-sulfate reductase (thioredoxin)" (GO: 0019379), and "sulfate assimilation" (GO: 0000103) that were assigned to downregulated genes in the $W z-W z$ isolate, were also enriched for the down-regulated genes in $\mathrm{Wz}-\mathrm{H}$ isolate. Sulfate reduction and sulfate assimilation are two important biological processes changing sulfate into sulfide, which is then used for the synthesis of methionine, cysteine, and other metabolites [45]. The biological significance of methionine is predominantly because the methionine codon AUG is the most common start codon that initiates protein synthesis [46]. Cysteine is a strong antioxidant with the potential to trap reactive oxygen species (ROS), stabilizes the high-order structures of proteins, and serves as an active center for the bioactivity of proteins [47]. When genes involved in sulfate assimilation and sulfate reduction processes are down-regulated, their effects on the synthesis and bioactivity of proteins can be profound. The fact that these $3 \mathrm{GO}$ terms were enriched for the down-regulated genes in both $W z-W z$ and $W z-H$ isolates seems to suggest that $W z$ resistance in tobacco was disrupting the protein synthesis in $P$. nicotianae as a defense mechanism.

In addition to the GO terms mentioned above, another 13 enriched GO terms were assigned to the down-regulated genes in $\mathrm{Wz}-\mathrm{H}$ isolate, including "oxidoreductase activity" (GO: 0016651, GO: 0000103, GO: 0009071; GO: 0016671). The "oxidation reduction process" catalyzed by oxidoreductases was found to be one of the two enriched GO terms distinguished the fungal pathogen Colletotrichum kahawae on coffee compared to its nonpathogenic sibling species [48], suggesting a substantial contribution of oxidoreductases in general pathogenicity in plant pathogens. Prospectively, a vital role of oxidoreductases in P. nicotianae aggressiveness is speculated. Down-regulation of genes annotated as oxidoreductases in the $\mathrm{Wz}-\mathrm{H}$ isolate could potentially hamper its performance on $\mathrm{K} 326 \mathrm{Wz} / \mathrm{Wz}$ compared to $W z-W z$ isolate.

Genes with differential transcript usage (DTU) also was investigated in the two isolates of $P$. nicotianae. Differential transcript usage is primarily the result of alternative splicing events that regulate translational processes. This allows for the formation of protein variants (isoforms) with different cellular functions or properties originating from a single gene, tremendously diversifying proteins encoded by genomes. Detection of genes with DTU has been widely used in RNAseq data analysis in human research [49]. The importance of DTU in genes in plant pathogens is largely unexplored, but a study with Pseudoperonospora cubensis showed that a functional effector protein PSCRXLR1 was generated from the alternative splicing of the PSC_781.4 gene that encodes a putative multi-drug transporter [50]. This finding prompted our interest in genes with DTU in P. nicotianae. A total of 27 genes in $\mathrm{Wz}-\mathrm{Wz}$ and 60 genes in $\mathrm{Wz}-\mathrm{H}$ with DTU were identified with predicted functional consequences. Among those genes, 33.3\% in $W z-W z$ and $23.3 \%$ in $W z-H$ were pathogenicity-associated genes found in PHIB. How DTU in the genes could alter the aggressiveness in P. nicotianae needs to be further researched, but DTU in genes such as PPTG_00215 encoding eukaryotic translation initiation factor 1A, PPTG_06129 encoding pre-mRNA 3' end processing protein WDR33, and PPTG_17135 encoding CCR4-NOT transcription complex subunit 1 signifies its role in translational biological processes in response to $\mathrm{Wz}$ resistance. Evidence of the importance of transcription factors in pathogen aggressiveness was confirmed in the genome-wide-association study (GWAS) in C. kahawae [48]. A slight change in pathogen genes or transcription factors associated in gene regulatory networks has been recognized to have a profound evolutionary impact [51]. 
Eight SNPs were identified between $W z-W z$ and $W z-H$. One SNP was located in the genetic region encoding a crinkler effector. Crinklers and RXLRs are two major classes of effectors secreted by oomycetes to facilitate pathogen infection [52]. The Crinkler protein family was first identified to cause leaf crinkling and necrosis when expressed in plants [53]. However, several Crinklers in P. infestans and P. capsici target the host nucleus during infection [54,55]. Effector proteins are coded by fast-evolving genes to overcome the immune system of the plants [56]. The SNP identified in the Crinkler effector coding region in our study may have critical roles in the interaction between $W z-W z$ isolate and tobacco genotype K $326 \mathrm{Wz} / \mathrm{Wz}$. Three SNPs occurred in gene PPTG_03590, with two of them occurring within 10 nucleobases in the gene. PPTG_03590 encodes a hypothetical protein concerved in Phytophthora species with unknown function. The high frequencey of SNPs occurring in this gene highlighted the importance of its encoding protein and the need for functional identification of the protein.

To have a comprehensive understanding of the $P$. nicotianae-tobacco interaction, the transcriptomic changes in tobacco were investigated. Given the different genetic backgrounds of $\mathrm{K} 326 \mathrm{Wz} / \mathrm{Wz}$ and Hicks, the DEGs detected when comparing $\mathrm{K} 326 \mathrm{Wz} / \mathrm{Wz}$ to Hicks inoculated with a given isolate of $P$. nicotianae could have resulted from the constitutive differences in gene expression in the two genotypes. To compensate for this, the 94 upregulated and 163 down-regulated genes commonly found in $\mathrm{K} 326 \mathrm{Wz} / \mathrm{Wz}$ compared to Hicks regardless of the isolate used for inoculation were considered as the background difference for the two tobacco genotypes. Among the 94 up-regulated genes in $\mathrm{K} 326 \mathrm{Wz} / \mathrm{Wz}$, a number of defense related genes were detected, including Nitab4.5_0007488g0040.1 and Nitab4.5_0001477g0080.1 that encodes pathogenesis-related (PR) protein 1a and five genes (Nitab4.5_0003154g0030.1, Nitab4.5_0000754g0140.1, Nitab4.5_0003324g0100.1, Nitab4.5_ 0014015g0010.1, Nitab4.5_0013087g0020.1) that encode proteinase inhibitors important in inhibiting pathogen proteases. The PR-protein 1a is required to initiate systemic acquired resistance (SAR), a defense response effective against a broad spectrum of plant pathogens [57]. Proteinase inhibitors play a fundamental role in plant basal defense by inhibiting pathogen proteases or by regulating endogenous plant proteases [58]. The functions of these genes were confirmed by GO enrichment analysis. GOs were enriched for up-regulated genes in the functional categories "serine-type endopeptidase inhibitor activity" (GO: 0004867), "peptidase inhibitor activity" (GO: 0030414), "peptidase regulator activity" (GO: 0061134), "endopeptidase inhibitor activity" (GO: 0004866), "endopeptidase regulator activity" (GO: 0061135). The elevated expression of these genes gives $\mathrm{K} 326 \mathrm{Wz} / \mathrm{Wz}$ an advantage in response to pathogen attack. Interestingly, compared to Hicks, a number of genes encoding glutathione S-transferase or glutathione S-transferase like protein were down regulated in $\mathrm{K} 326 \mathrm{Wz} / \mathrm{Wz}$. Glutathione S-transferase are multifunctional enzymes ubiquitous in plants. They are highly inducible by a wide range of stresses including pathogen infection [59]. In a previous study on black shank resistance in tobacco, plants that had silenced glutathione S-transferase had increased resistance to $P$. nicotianae infection, suggesting that glutathione S-transferase was able to act as a negative regulator of defense responses in tobacco [60]. The connection between the down-regulated expression of glutathione S-transferase genes and up-regulated defense-associated genes in $\mathrm{K} 326 \mathrm{Wz} / \mathrm{Wz}$ remains to be explored.

For the down-regulated genes identified exclusively in $\mathrm{K} 326 \mathrm{Wz} / \mathrm{Wz}$ inoculated with the $W z-W z$ isolate, enriched GO terms included "nucleosome organization" (GO: 0034728), "nucleosome assembly" (GO: 0006334), "chromosome organization" (GO: 0051276), "chromatin assembly or disassembly" (GO: 0006333), "DNA packaging complex" (GO: 0044815), "protein complex assembly" (GO: 0006461), suggesting the nuclear biosynthesis processes were impeded in $\mathrm{K} 326 \mathrm{Wz} / \mathrm{Wz}$ compared to Hicks when inoculated with the $\mathrm{Wz}-\mathrm{Wz}$ isolate. This phenomenon was not observed when $\mathrm{K} 326 \mathrm{Wz} / \mathrm{Wz}$ was inoculated with the $W z-\mathrm{H}$ isolate. Along with previous studies where Phytophthora targeted host nuclei to suppress defense $[54,61]$, our observations suggested that isolates of P. nicotianae adapted 
to partial resistance in tobacco were able to interrupt biological processes in host nuclei to facilitate infection.

\section{Conclusions}

Few molecular studies have been completed to identify factors that might determine the overall aggressiveness of plant pathogens. Quantitative traits such as aggressiveness are challenging to dissect. A GWAS study on aggressiveness in C. kahawae strongly suggested that aggressiveness is associated with some small effect SNPs and is not regulated by causal mutations, which would indicate that aggressiveness might be a variable and very complex trait regulated by differential gene expression and corresponding regulatory mechanisms [48]. Our study was designed to enhance our understanding of the genetic mechanisms underlying $P$. nicotianae adaptation to partial resistance in tobacco using dual RNAseq. Overall, results from this study suggest that isolates of $P$. nicotianae adapted to partial resistance are able to recruit a high percentage of pathogenicity-associated genes when infecting a partially resistant genotype, and are more tolerant to the defenses expressed by $W z$ resistance. Finally, isolates adapted to the source of partial resistance used were able to severely hinder nuclear synthesis processes in $\mathrm{K} 326 \mathrm{Wz} / \mathrm{Wz}$.

$\mathrm{Wz}$ resistance in $\mathrm{K} 326 \mathrm{Wz} / \mathrm{Wz}$ potentially disrupts protein synthesis in $P$. nicotianae as a defense mechanism. A broad spectrum and a high level of expression of defense related genes were recruited by $\mathrm{K} 326 \mathrm{Wz} / \mathrm{Wz}$ to inhibit non-adapted isolates of $P$. nicotianae compared to the adapted isolate. This was confirmed by the observation of a wide range of biological activities were affected by the down-regulated DEGs in the non-adapted isolate on $\mathrm{K} 326 \mathrm{Wz} / \mathrm{Wz}$.

It would be beneficial if additional studies involving more isolates with distinct aggressiveness levels could be used to confirm our findings. Notwithstanding, sets of differentially expressed genes and genes with differential transcript usage were generated and can be researched via additional functional analyses to substantiate their roles in $P$. nicotianae aggressiveness. These findings provide a foundation for further investigation of the molecular mechanisms underlying pathogen adaptation to partial resistance in host plants.

Supplementary Materials: The following are available online at https: / www.mdpi.com/article / 10.3390 /agronomy11040656/s1, Table S1: PHIB blast results for DEGs identified in the $W z-W z$ and $\mathrm{Wz}-\mathrm{H}$ isolates of Phytophthora nicotianae, Table S2: DEGs identified in the $\mathrm{Wz}-\mathrm{Wz}$ and $\mathrm{Wz}-\mathrm{H}$ isolates of Phytophthora nicotianae with differential transcript usage (DTU), Table S3: PHIB blast results for DEGs identified in $W z-W z$ and $W z-H$ isolates of Phytophthora nicotianae with differential transcript usage (DTU), Table S4: DEGs identified in $\mathrm{K} 326 \mathrm{Wz} / \mathrm{Wz}$ inoculated with either $\mathrm{Wz}-\mathrm{Wz}$ or $\mathrm{Wz}-\mathrm{H}$ isolate of Phytophthora nicotianae.

Author Contributions: J.J. and H.D.S. conceived and designed the experiments; J.J. performed the experiments; J.J. and R.S. analyzed the data; R.S.L. contributed experimental materials; J.J., H.D.S., and R.S.L. wrote the paper. All authors have read and agreed to the published version of the manuscript.

Funding: This research received no external funding.

Institutional Review Board Statement: Not applicable.

Informed Consent Statement: Not applicable.

Data Availability Statement: The datasets generated during the current study are available in the GEO repository with GEO accession GSE168516.

Conflicts of Interest: The authors declare no conflict of interest. 


\section{References}

1. Oerke, E.C. Crop losses to pests. J. Agric. Sci. 2006, 144, 31-43. [CrossRef]

2. Mundt, C.C. Durable resistance: A key to sustainable management of pathogens and pests. Infect. Genet. Evol. $2014,27,446-455$. [CrossRef]

3. McDonald, B.; Linde, C. The population genetics of plant pathogens and breeding strategies for durable resistance. Euphytica 2002, 124, 163-180. [CrossRef]

4. Cowger, C.; Mundt, C.C. Aggressiveness of Mycosphaerella graminicola isolates from susceptible and partially resistant wheat cultivars. Phytopathology 2002, 92, 624-630. [CrossRef]

5. Montarry, J.; Glais, I.; Corbiere, R.; Andrivon, D. Adaptation to the most abundant host genotype in an agricultural plant-pathogen system-potato late blight. J. Evol. Biol. 2008, 21, 1397-1407. [CrossRef] [PubMed]

6. Delmotte, F.; Mestre, P.; Schneider, C.; Kassemeyer, H.H.; Kozma, P.; Richart-Cervera, S.; Rouxel, M.; Delière, L. Rapid and multiregional adaptation to host partial resistance in a plant pathogenic oomycete: Evidence from European populations of Plasmopara viticola, the causal agent of grapevine downy mildew. Infect. Genet. Evol. 2014, 27, 500-508. [CrossRef]

7. Na, R.; Gijzen, M. Escaping host immunity: New tricks for plant pathogens. PLoS Pathog. 2016, 12, e1005631. [CrossRef] [PubMed]

8. Wang, Q.; Li, T.; Zhong, C.; Luo, S.; Xu, K.; Gu, B.; Meng, Y.; Tyler, B.M.; Shan, W. Small RNAs generated by bidirectional transcription mediate silencing of RXLR effector genes in the oomycete Phytophthora sojae. Phytopathol. Res. 2019, 1, 18. [CrossRef]

9. Cline, E.T.; Farr, D.F.; Rossman, A.Y. A synopsis of Phytophthora with accurate scientific names, host range, and geographic distribution. Plant Health Prog. 2008, 9, 32. [CrossRef]

10. Gallup, C.A.; Sullivan, M.J.; Shew, H.D. Black Shank of Tobacco. In The Plant Health Instructor; The American Phytopathological Society: St. Paul, MN, USA, 2006.

11. Sullivan, M.J.; Parks, E.J.; Cubeta, M.A.; Gallup, C.A.; Melton, T.A.; Moyer, J.W.; Shew, H.D. An assessment of the genetic diversity in a field population of Phytophthora nicotianae with a changing race structure. Plant Dis. 2010, 94, 455-460. [CrossRef]

12. Dukes, P.D.; Apple, J.L. Influence of host passage on virulence of Phytophthora parasitica var. nicotianae. Plant Dis. Rep. 1961, 45,362 .

13. Sullivan, M.J.; Melton, T.A.; Shew, H.D. Managing the race structure of Phytophthora parasitica var. nicotianae with cultivar rotation. Plant Dis. 2005, 89, 1285-1294. [CrossRef]

14. McCorkle, K.L.; Drake-Stowe, K.; Lewis, R.S.; Shew, H.D. Characterization of Phytophthora nicotianae resistance conferred by the introgressed Nicotiana rustica region, Wz, in flue-cured tobacco. Plant Dis. 2018, 102, 309-317. [CrossRef]

15. McCorkle, K.L. Characterization of the Tobacco Pathogen Phytophthora nicotianae and Its Ability to Adapt Tohost Resistance Genes. Ph.D. Thesis, North Carolina State University, Raleigh, NC, USA, 2016.

16. Jin, J.; Shew, H.D. Components of aggressiveness in Phytophthora nicotianae during adaptation to multiple sources of partial resistance in tobacco. Plant Dis. 2020. [CrossRef] [PubMed]

17. Jin, J. Characterization of Phytophthora nicotianae Following Adaptation to Partial Resistance in Tobacco. Ph.D. Thesis, North Carolina State University, Raleigh, NC, USA, 2020.

18. Andrews, S. FastQC: A Quality Control Tool for High Throughput Sequence Data; Babraham Inst.: Cambridge, UK, 2010.

19. Kim, D.; Langmead, B.; Salzberg, S.L. HISAT: A fast spliced aligner with low memory requirements. Nat. Methods 2015, 12, 357-360. [CrossRef]

20. Liao, Y.; Smyth, G.K.; Shi, W. featureCounts: An efficient general purpose program for assigning sequence reads to genomic features. Bioinformatics 2013, 30, 923-930. [CrossRef] [PubMed]

21. Robinson, M.D.; McCarthy, D.J.; Smyth, G.K. edgeR: A Bioconductor package for differential expression analysis of digital gene expression data. Bioinformatics 2010, 26, 139-140. [CrossRef]

22. Apweiler, R.; Bairoch, A.; Wu, C.H.; Barker, W.C.; Boeckmann, B.; Ferro, S.; Gasteiger, E.; Huang, H.; Lopez, R.; Magrane, M.; et al. UniProt: The universal protein knowledgebase. Nucleic Acids Res. 2004, 32, D115-D119. [CrossRef]

23. Maere, S.; Heymans, K.; Kuiper, M. BiNGO: A Cytoscape plugin to assess overrepresentation of gene ontology categories in biological networks. Bioinformatics 2005, 21, 3448-3449. [CrossRef]

24. Shannon, P.; Markiel, A.; Ozier, O.; Baliga, N.S.; Wang, J.T.; Ramage, D.; Amin, N.; Schwikowski, B.; Ideker, T. Cytoscape: A software environment for integrated models of biomolecular interaction networks. Genome Res. 2003, 13, 2498-2504. [CrossRef]

25. Ogata, H.; Goto, S.; Sato, K.; Fujibuchi, W.; Bono, H.; Kanehisa, M. KEGG: Kyoto encyclopedia of genes and genomes. Nucleic Acids Res. 1999, 27, 29-34. [CrossRef] [PubMed]

26. Xie, C.; Mao, X.; Huang, J.; Ding, Y.; Wu, J.; Dong, S.; Kong, L.; Gao, G.; Li, C.Y.; Wei, L. KOBAS 2.0: A web server for annotation and identification of enriched pathways and diseases. Nucleic Acids Res. 2011, 39, W316-W322. [CrossRef]

27. Urban, M.; Cuzick, A.; Rutherford, K.; Irvine, A.; Pedro, H.; Pant, R.; Sadanadan, V.; Khamari, L.; Billal, S.; Mohanty, S.; et al. PHI-base: A new interface and further additions for the multi-species pathogen-host interactions database. Nucleic Acids Res. 2017, 45, D604-D610. [CrossRef] [PubMed]

28. Pertea, M.; Pertea, G.M.; Antonescu, C.M.; Chang, T.C.; Mendell, J.T.; Salzberg, S.L. StringTie enables improved reconstruction of a transcriptome from RNA-seq reads. Nat. Biotechnol. 2015, 33, 290-295. [CrossRef]

29. Vitting-Seerup, K.; Sandelin, A. IsoformSwitchAnalyzeR: Analysis of changes in genome-wide patterns of alternative splicing and its functional consequences. Bioinformatics 2019, 35, 4469-4471. [CrossRef] 
30. Li, H.; Handsaker, B.; Wysoker, A.; Fennell, T.; Ruan, J.; Homer, N.; Marth, G.; Abecasis, G.; Durbin, R. The sequence alignment/map format and SAMtools. Bioinformatics 2009, 25, 2078-2079. [CrossRef]

31. Edwards, K.D.; Fernandez-Pozo, N.; Drake-Stowe, K.; Humphry, M.; Evans, A.D.; Bombarely, A.; Allen, F.; Hurst, R.; White, B.; Kernodle, S.P.; et al. A reference genome for Nicotiana tabacum enables map-based cloning of homeologous loci implicated in nitrogen utilization efficiency. BMC Genom. 2017, 18, 448. [CrossRef] [PubMed]

32. Du, Z.; Zhou, X.; Ling, Y.; Zhang, Z.; Su, Z. agriGO: A GO analysis toolkit for the agricultural community. Nucleic Acids Res. 2010, 38, W64-W70. [CrossRef] [PubMed]

33. Yan, H.Z.; Liou, R.F. Selection of internal control genes for real-time quantitative RT-PCR assays in the oomycete plant pathogen Phytophthora parasitica. Fungal Genet. Biol. 2006, 43, 430-438. [CrossRef]

34. Iida, Y.; van't Hof, P.; Beenen, H.; Mesarich, C.; Kubota, M.; Stergiopoulos, I.; Mehrabi, R.; Notsu, A.; Fujiwara, K.; Bahkali, A.; et al. Novel mutations detected in avirulence genes overcoming tomato $\mathrm{Cf}$ resistance genes in isolates of a Japanese population of Cladosporium fulvum. PLoS ONE 2015, 10, e0123271. [CrossRef]

35. Morris, P.F.; Phuntumart, V. Inventory and comparative evolution of the ABC superfamily in the genomes of Phytophthora ramorum and Phytophthora sojae. J. Mol. Evol. 2009, 68, 563-575. [CrossRef]

36. Urban, M.; Bhargava, T.; Hamer, J.E. An ATP-driven efflux pump is a novel pathogenicity factor in rice blast disease. EMBO J. 1999, 18, 512-521. [CrossRef] [PubMed]

37. Hayashi, K.; Schoonbeek, H.J.; Sugiura, H.; De Waard, M.A. Multidrug resistance in Botrytis cinerea associated with decreased accumulation of the azole fungicide oxpoconazole and increased transcription of the ABC transporter gene BcatrD. Pestic. Biochem. Physiol. 2001, 70, 168-179. [CrossRef]

38. Lee, Y.J.; Yamamoto, K.; Hamamoto, H.; Nakaune, R.; Hibi, T. A novel ABC transporter gene ABC2 involved in multidrug susceptibility but not pathogenicity in rice blast fungus, Magnaporthe grisea. Pestic. Biochem. Physiol. 2005, 81, 13-23. [CrossRef]

39. Liu, H.; Ma, X.; Yu, H.; Fang, D.; Li, Y.; Wang, X.; Wang, W.; Dong, Y.; Xiao, B. Genomes and virulence difference between two physiological races of Phytophthora nicotianae. Gigascience 2016, 5, 3. [CrossRef]

40. Levine, B.; Klionsky, D.J. Development by self-digestion: Molecular mechanisms and biological functions of autophagy. Dev. Cell 2004, 6, 463-477. [CrossRef]

41. Liu, X.H.; Lu, J.P.; Lin, F.C. Autophagy during conidiation, conidial germination and turgor generation in Magnaporthe grisea. Autophagy 2007, 3, 472-473. [CrossRef] [PubMed]

42. Ren, W.; Zhang, Z.; Shao, W.; Yang, Y.; Zhou, M.; Chen, C. The autophagy-related gene BcATG1 is involved in fungal development and pathogenesis in Botrytis cinerea. Mol. Plant Pathol. 2017, 18, 238-248. [CrossRef] [PubMed]

43. Lv, W.; Wang, C.; Yang, N.; Que, Y.; Talbot, N.J.; Wang, Z. Genome-wide functional analysis reveals that autophagy is necessary for growth, sporulation, deoxynivalenol production and virulence in Fusarium graminearum. Sci. Rep. 2017, 7, 11062. [CrossRef]

44. Chen, L.; Zhang, X.; Wang, W.; Geng, X.; Shi, Y.; Na, R.; Dou, D.; Li, H. Network and role analysis of autophagy in Phytophthora sojae. Sci. Rep. 2017, 7, 1879. [CrossRef]

45. Patron, N.J.; Durnford, D.G.; Kopriva, S. Sulfate assimilation in eukaryotes: Fusions, relocations and lateral transfers. BMC Evol. Biol. 2008, 8, 39. [CrossRef] [PubMed]

46. Demongeot, J.; Seligmann, H. Why is AUG the start codon? Theoretical minimal RNA rings: Maximizing coded information biases 1st codon for the universal initiation codon AUG. BioEssays 2020, 42, 1900201. [CrossRef]

47. Netto, L.E.S.; de Oliveira, M.A.; Monteiro, G.; Demasi, A.P.D.; Cussiol, J.R.R.; Discola, K.F.; Demasi, M.; Silva, G.M.; Alves, S.V.; Faria, V.G.; et al. Reactive cysteine in proteins: Protein folding, antioxidant defense, redox signaling and more. Comp. Biochem. Physiol. C Toxicol. Pharmacol. 2007, 146, 180-193. [CrossRef] [PubMed]

48. Vieira, A.; Silva, D.N.; Várzea, V.; Paulo, O.S.; Batista, D. Genome-wide signatures of selection in Colletotrichum kahawae reveal candidate genes potentially involved in pathogenicity and aggressiveness. Front. Microbiol. 2019, 10, 1374. [CrossRef]

49. Liu, Y.; Gonzàlez-Porta, M.; Santos, S.; Brazma, A.; Marioni, J.C.; Aebersold, R.; Venkitaraman, A.R.; Wickramasinghe, V.O. Impact of alternative splicing on the human proteome. Cell Rep. 2017, 20, 1229-1241. [CrossRef]

50. Savory, E.A.; Zou, C.; Adhikari, B.N.; Hamilton, J.P.; Buell, C.R.; Shiu, S.H.; Day, B. Alternative splicing of a multi-drug transporter from Pseudoperonospora cubensis generates an RXLR effector protein that elicits a rapid cell death. PLoS ONE 2012, 7, e34701. [CrossRef]

51. De Fine Licht, H.H. Does pathogen plasticity facilitate host shifts? PLoS Pathog. 2018, 14, e1006961. [CrossRef]

52. Stassen, J.H.; Van den Ackerveken, G. How do oomycete effectors interfere with plant life? Curr. Opin. Plant Biol. 2011, 14, 407-414. [CrossRef]

53. Torto, T.A.; Li, S.; Styer, A.; Huitema, E.; Testa, A.; Gow, N.A.; Van West, P.; Kamoun, S. EST mining and functional expression assays identify extracellular effector proteins from the plant pathogen Phytophthora. Genome Res. 2003, 13, 1675-1685. [CrossRef] [PubMed]

54. Schornack, S.; van Damme, M.; Bozkurt, T.O.; Cano, L.M.; Smoker, M.; Thines, M.; Gaulin, E.; Kamoun, S.; Huitema, E. Ancient class of translocated oomycete effectors targets the host nucleus. Proc. Natl. Acad. Sci. USA 2010, 107, 17421-17426. [CrossRef]

55. Stam, R.; Jupe, J.; Howden, A.J.; Morris, J.A.; Boevink, P.C.; Hedley, P.E.; Huitema, E. Identification and characterisation CRN effectors in Phytophthora capsici shows modularity and functional diversity. PLoS ONE 2013, 8, e59517. [CrossRef]

56. Frantzeskakis, L.; Kusch, S.; Panstruga, R. The need for speed: Compartmentalized genome evolution in filamentous phytopathogens. Mol. Plant Pathol. 2019, 20, 3-7. [CrossRef] [PubMed] 
57. Alexander, D.; Goodman, R.M.; Gut-Rella, M.; Glascock, C.; Weymann, K.; Friedrich, L.; Maddox, D.; Ahl-Goy, P.; Luntz, T.; Ward, E.S. Increased tolerance to two oomycete pathogens in transgenic tobacco expressing pathogenesis-related protein 1a. Proc. Natl. Acad. Sci. USA 1993, 90, 7327-7331. [CrossRef] [PubMed]

58. Jashni, M.K.; Mehrabi, R.; Collemare, J.; Mesarich, C.H.; de Wit, P.J. The battle in the apoplast: Further insights into the roles of proteases and their inhibitors in plant-pathogen interactions. Front. Plant Sci. 2015, 6, 584. [CrossRef] [PubMed]

59. Gullner, G.; Komives, T.; Király, L.; Schröder, P. Glutathione S-transferase enzymes in plant-pathogen interactions. Front. Plant Sci. 2018, 9, 1836. [CrossRef] [PubMed]

60. Hernández, I.; Chacón, O.; Rodriguez, R.; Portieles, R.; López, Y.; Pujol, M.; Borrás-Hidalgo, O. Black shank resistant tobacco by silencing of glutathione S-transferase. Biochem. Biophys. Res. Commun. 2009, 387, 300-304. [CrossRef]

61. Stam, R.; Howden, A.J.M.; Delgado Cerezo, M.; Amaro, T.M.; Motion, G.B.; Pham, J.; Huitema, E. Characterization of cell death inducing Phytophthora capsici CRN effectors suggests diverse activities in the host nucleus. Front. Plant Sci. 2013, 4, 387. [CrossRef] [PubMed] 